http://dx.doi.org/10.1007/s00382-009-0655-z

(c) 2009 Springer-Verlag

The original publication is available at http://www.springerlink.com

\title{
Low and high frequency Madden-Julian oscillations in austral summer: interannual variations
}

\author{
Takeshi Izumo ${ }^{1,2, ~}{ }^{*}$, Sébastien Masson ${ }^{2}$, Jérome Vialard², Clément de Boyer Montegut ${ }^{3}$,
} Swadhin K. Behera ${ }^{1}$, Gurvan Madec ${ }^{2}$, Keiko Takahashi $^{4}$ and Toshio Yamagata ${ }^{1,5}$

\author{
${ }^{1}$ Institute For Global Change (JAMSTEC), Yokohama, Japan \\ ${ }^{2}$ LOCEAN, IRD-CNRS-UPMC, Paris, France \\ 3 IFREMER, Brest, France \\ ${ }^{4}$ Earth Simulator Center (JAMSTEC), Yokohama, Japan \\ ${ }^{5}$ University of Tokyo, Tokyo, Japan \\ *: Corresponding author : Takeshi Izumo, email address : izumo@jamstec.go.jp
}

\begin{abstract}
:
The Madden-Julian oscillation (MJO) is the main component of intraseasonal variability of the tropical convection, with clear climatic impacts at an almost-global scale. Based on satellite observations, it is shown that there are two types of austral-summer MJO events (broadly defined as 30-120 days convective variability with eastward propagation of about $5 \mathrm{~m} / \mathrm{s}$ ). Equatorial MJO events have a period of 30-50 days and tend to be symmetric about the equator, whereas $\mathrm{MJO}$ events centered near $8^{\circ} \mathrm{S}$ tend to have a longer period of 55-100 days. The lower-frequency variability is associated with a strong upper-ocean response, having a clear signature in both sea surface temperature and its diurnal cycle. These two MJO types have different interannual variations, and are modulated by the Indian Ocean Dipole (IOD). Following a negative IOD event, the lower-frequency southern MJO variability increases, while the higher-frequency equatorial MJO strongly diminishes. We propose two possible explanations for this change in properties of the MJO. One possibility is that changes in the background atmospheric circulation after an IOD favour the development of the low-frequency MJO. The other possibility is that the shallower thermocline ridge and mixed layer depth, by enhancing SST intraseasonal variability and thus ocean-atmosphere coupling in the southwest Indian Ocean (the breeding ground of southern MJO onset), favour the lower-frequency southern MJO variability.
\end{abstract}

Keywords: Intraseasonal Madden-Julian oscillation (MJO)-Seychelles-Chagos thermocline ridge/thermocline dome of the Indian Ocean - Indian Ocean dipole (IOD) - El Nino southern oscillation (ENSO) - Diurnal cycle - Oceanic diurnal warm layers - Air-sea interactions - Ocean-atmosphere coupling - Interannual variations - Mixed layer - Australian weather 


\section{Introduction}

The Madden-Julian Oscillation (MJO) is the main component of intraseasonal (30-100 days) variability of the tropical climate, and has strong societal impacts at an almost global scale (Madden and Julian 1972, 1994; Zhang 2005). The Madden-Julian oscillation has a strong seasonality and its central latitude follows roughly the movements of the Inter-Tropical Convergence Zone (ITCZ; Zhang and Dong 2004). The MJO can be very broadly defined as eastward-propagating perturbations of the tropical convection in the 30-100 days range. During the MJO active phase, anomalous convection develops over the tropical Indian Ocean and propagates eastward at a slow speed of about $5 \mathrm{~m} / \mathrm{s}$ into the Pacific Ocean, before fading at the eastern edge of the ITCZ/South Pacific Convergence Zone (SPCZ).

The eastward propagation of the MJO is slow compared to atmospheric moist Kelvin waves $(\sim 15-20 \mathrm{~m} / \mathrm{s}$, Wheeler and Kiladis 1999), and many mechanisms have been proposed to explain this slow propagation. The most prevalent one seems to be the frictionalconvective interaction with dynamics". The Kelvin-Rossby wave structure of the response to heating (Gill 1988) is associated with frictional convergence in the boundary layer to the east of the convective center (Wang 1988), providing a low-level humidity source. This frictional convergence process interacts with CISK (conditional instability of the second kind, Charney and Eliassen 1964) mechanism - that relates low-level convergence (divergence) to atmospheric heating (cooling) - to create a slow eastward propagating mode.

While coupling between convection and dynamics probably holds many keys to the MJO properties, the coupling with the oceanic mixed layer also seems to influence the MJO. The ocean surface layer is the main source of moisture for the atmosphere $(5 \mathrm{~m}$ of water has the same heat capacity as the entire tropical tropospheric column) and varies significantly with the MJO. MJO-related, surface, latent-heat and short-wave flux variations can exceed +/- 
$50 \mathrm{~W} \mathrm{~m}^{-2}$ and zonal wind variations can exceed $5 \mathrm{~m} / \mathrm{s}$ (see reviews of Hendon 2005, Zhang 2005, Waliser 2005). Prior to an MJO active phase, clear-sky and low wind-speed conditions prevail, warming SST through diminished air-sea fluxes and oceanic mixing (e.g. Waliser et al. 1999; Inness and Slingo 2003; Maloney and Sobel 2004). These SST anomalies can in turn favour eastward propagation of MJO convection. The MJO is indeed generally more realistic, with enhanced eastward propagation, in AGCMs coupled to a slab-ocean or Ocean GCM (Zhang et al. 2005; Watterson and Syktus 2007), even if a counter-example exists (Hendon 2000). Coupling can also improve forecasts of the MJO (see review of Waliser 2005, and also Woolnough et al. 2007).

The recent advent of satellite microwave data has highlighted regions of strong SST response to the MJO during austral summer (Harrison and Vecchi 2001; Duvel et al. 2004; Saji et al. 2006; Duvel and Vialard 2007). One of these regions is the thermocline ridge between $5^{\circ} \mathrm{S}$ and $10^{\circ} \mathrm{S}$ in the Indian Ocean, also known as Seychelles-Chagos Thermocline Ridge (SCTR, Xie et al. 2002, Yokoi et al. 2008, Hermes and Reason 2008). The climatological wind curl in this region favours a shallow thermocline, and this property maintains a shallow, reactive mixed layer, which might explain the strong SST variability in this region (Duvel and Vialard 2007). The $5^{\circ} \mathrm{S}-10^{\circ} \mathrm{S}$ band in the Indian Ocean exhibits a strong heat content variability at interannual timescales (Masumoto and Meyers, 1998), which seems to be more directly caused by the Indian Ocean Dipole (IOD, Saji et al. 1999; Webster et al. 1999) than by El Niño / La Niña (Rao and Behera 2005). Duvel et al. (2004) and Vialard et al. (2009) showed that interannual variability of the thermal content along the SCTR could modulate the mixed layer depth, and thus the SST response to the MJO. They also proposed that this SST modulation might feedback onto the atmosphere and modulate the interannual variability of the MJO. 
A thin $(\leq 1 \mathrm{~m})$, warm, mixed layer can develop during the day throughout MJO break phase due to low-wind and clear-sky conditions. Such oceanic layer can strongly enhance SST diurnal peak and amplitude (by about $1^{\circ}$ to $2^{\circ} \mathrm{C}$ ), and daily mean (by about $0.2^{\circ}-0.5^{\circ} \mathrm{C}$ ) (e.g. Bernie et al. 2005). Diurnal warm layers often have broad horizontal extents (larger than $\sim 500-1000 \mathrm{~km}$ ). They appear in already warm regions (mean SST $>28^{\circ} \mathrm{C}$ ), which are very sensitive to small SST changes because of the non-linearity of the Clausius-Clapeyron equation. They favour diurnal convection by increasing evaporation, warming and destabilizing the low-level atmosphere (Kawai and Wada 2007; Yasunaga et al. 2008), and help to moisten the lower troposphere gradually during the MJO break phase, creating favourable conditions for deep convection and MJO onset (Godfrey et al. 1998). So they possibly play an essential role in onset, amplitude, propagation and/or termination of the MJO

100 (e.g. Bernie et al. 2007, 2008; review of Kawai and Wada 2007). A recent study even showed that taking the diurnal cycle into account could improve forecasts of the MJO (Woolnough et al. 2007).

Early descriptions of the MJO coined it as the 30-60 day oscillation" (e.g. Madden and Julian, 1994). The MJO period band is in fact broader during boreal winter ( $\sim 30-100$ days) compared to boreal summer ( 30-50 days) (e.g. Zhang and Dong 2004). Saji et al. (2006) pointed out that the timescale of convective variability was longer around $8^{\circ} \mathrm{S}$ than at the equator in the eastern Indian Ocean, and suggested that there might be two types of intraseasonal variability in the Indian Ocean (a 30-50 day mode in the equatorial band and a lower frequency mode further south). They also showed that the SST response to the southern

110 mode was larger, possibly because of longer periods (Duvel and Vialard 2007).

111 In this paper, we investigate in more detail the differences in timescales and properties

112 of the austral-summer MJOs along the equator and in the $5^{\circ}-10^{\circ} \mathrm{S}$ band. We first analyze how 113 different the oceanic and atmospheric anomalies related to MJO are in both cases, 
114 distinguishing precisely the two MJO types ${ }^{1}$. We then investigate how both types of MJO

115 variability are influenced by interannual variability, notably in the SCTR region as suggested

116 in several earlier studies (e.g., Duvel et al., 2004; Saji et al., 2006: Duvel and Vialard, 2007;

117 Vialard et al. 2008, 2009). Section 2 presents the data and analysis methods we used. In

118 section 3, we analyze the observed oceanic and atmospheric anomalies related to the two

119 MJO types. The higher-frequency MJO (HF-MJO, 35-50 days) tends to be symmetric with

120 respect to the equator, while the lower frequency MJO (LF-MJO, 55-100 days) is maximum

121 around $8^{\circ} \mathrm{S}$. The LF-MJO is associated with stronger SST, SST diurnal cycle and upper-

122 ocean, heat-content signatures. Section 4 investigates interannual variations of the two MJO

123 types, and shows that the lower-frequency type has larger amplitude following negative IOD

124 years. Section 5 then provides a summary and suggests mechanisms that could explain the

125 difference in properties between the two MJO types. These hypotheses will be tested through

126 a set of coupled general circulation model (CGCM) in a sequel to this study.

127

\section{2. Data and methods}

\subsection{Observations}

Outgoing Longwave Radiation (OLR) is a classical proxy for deep convection in the

131 tropics and widely used to characterize the MJO. We use the daily $2.5^{\circ} \times 2.5^{\circ}$ interpolated

132 product from (Liebmann and Smith 1996) available from 1974 to 2008 with a gap in 1978.

133 The Tropical Rainfall Measuring Mission Microwave Imager (TMI) (3-day mean every

134 day, 1998-2007; Wentz et al. 2000) is used to investigate SST intraseasonal variability,

\footnotetext{
${ }^{1}$ We prefer to use the term type" rather than mode", as the broad properties (eastward propagation in the 30-100 day band) and main mechanim (coupling between atmospheric dynamics and convection) are likely the same for the two MJO types, even if oceanatmosphere interactions could also play an important role for the low-frequency MJO type.
} 
135 whereas NOAA Optimum Interpolation SST V2 data (for 1981-2007, Reynolds et al. 2002)

136 and Extended Reconstructed SST (ERSST V2 for 1974-1981; Smith and Reynolds 2004) are

137 used to study interannual timescales. Afternoon and night SST from the Advanced Very High

138 Resolution Radiometer (4 km AVHRR Pathfinder Version 5.0) are used to estimate the

139 variations in amplitude of SST diurnal cycle for 1985-2002, and also in daily mean SST for

140 1985-2007. As AVHRR SST is sensitive to cloud cover, we kept only data with a quality flag

141 higher or equal to 4 (on a range from 1 to 7 ). We also pay particular attention on drifts in

142 passing local time during the day (Stuart-Menteth et al. 2003) and excluded periods when

143 day-pass is too late. Note that our AVHRR-based estimate of SST diurnal amplitude is

144 weaker than TMI measurements (available on a shorter period) by about a factor of 2 (Kawai

145 and Wada 2007). With two passes per day, it cannot provide a precise estimate of the absolute

146 SST diurnal amplitude, but it can help to assess the variability of SST diurnal amplitude.

147 To assess observed wind variability on the longest period possible, we merged data

148 from daily Quick Scatterometer (QUIKSCAT, 1999-2007, http://www.ssmi.com/qscat/),

149 weekly European Remote Sensing (ERS) scatterometers winds (from April 1992,

150 http://www.ifremer.fr/cersat, Bentamy et al. 1996) and daily Special Sensor Microwave /

151 Imager (SSMI) wind speed (from 1987, Goodberlet et al. 1989), the later being combined

152 with ECMWF reanalysis wind direction [Atlas et al. 1996].

153 Ocean heat content and thermocline depth variations are investigated using sea level 154 anomaly (SLA) from TOPEX/Poseidon and JASON satellites (AVISO product). We also use 155 mixed layer depth estimates form oceanic reanalyzes produced by the CERFACS within the 156 ENSEMBLES project (Weaver et al. 2005; Daget et al. 2008).

157 All satellite data are regridded on a $1^{\circ} \times 1^{\circ}$ grid, except for OLR, and averaged on

158 pentads. For each dataset, the pentad seasonal cycle, calculated over the longest available 159 period, is removed to obtain interannual anomalies. 


\subsection{Methods}

In this paper, we use a space-time spectral analysis similar to that of previous studies

162 (Takayabu 1994; Wheeler and Kiladis 1999) to evaluate the timescales of the eastward

163 propagating components of the convection and its latitudinal distribution.

We will use a lag-composite analysis to extract the two intraseasonal types of convective variability. For that, we use the $90^{\circ} \mathrm{E}, 10^{\circ} \mathrm{S}-10^{\circ} \mathrm{N}$ average, OLR anomaly during DJFM as an index of convective activity. This index will be band-pass filtered in three as to obtain filtered indices of MJO for these timescales $\left(O L R_{f i l t 90^{\circ} \mathrm{E}}\right)$. (Note that as a Lanczos will actually contain some information related to signals in an extended boreal winter season,

171 larger by about half of the MJO period (i.e. about one month) on each side of DJFM (i.e. 172 NDJFMA).) This index can be used to make weighted composites for the active (filtered 173 OLR $<0$ ) phases of the MJO, where the weight is the filtered index when negative at day 0 , so $O L R_{\text {filt } 90^{\circ} E} \times H\left(-O L R_{\text {fil } 90^{\circ} E}\right)$ where $H(x)$ denotes the Heavyside function $(H=0$ if $x<0, H=1$

175 if $x>0$ ). The weighted composite (wcompos) of a field $Y$ (e.g. SST, wind, OLR, possibly 176 lagged with $O L R_{f i l t 90^{\circ} E}$ to obtain lag-composites) is computed using the formulae:

$$
\underset{\square \operatorname{wompos}(Y)}{\square}=\frac{\int Y \times O L R_{\text {filt } 90^{\circ} E} \times H\left(-O L R_{\text {fil } 90^{\circ} E}\right) d t}{\int O L R_{\text {fil } 90^{\circ} E} \times H\left(-O L R_{\text {fil } 90^{\circ} E}\right) d t}
$$

178 These weighted composites are quite similar to a linear regression for only negative values of

179 the MJO index $O L R_{\text {filt } 90^{\circ} E}$, giving similar results to simple composites but with more

180 statistical information. The interest of weighted composites compared to standard linear 181 regression is that the active and break phases of the MJO can be clearly separated, so that the 182 MJO phase captured by the statistical method is well known. Note that the composite analyses 183 presented here were also done with linear regressions and give rather similar results. The 
184 fields to be composited on MJO index are band-pass filtered in the 30-120 days band, except

185 if noted. Weighted composites are computed on the MJO index of December to March 186 (DJFM) period.

187 In section 4 on MJO interannual variations, the weighted composites have also been 188 computed using the MJO index of Wheeler and Hendon (2004). The negative values of their 189 RMM2 index correspond to an active phase of the MJO over the eastern Indian Ocean, similar 190 to the MJO index previously defined. As this index is not filtered temporally, it can be helpful 191 to test the possible sensitivity of the results in section 4 to the temporal filter used. Similar 192 results were obtained for the interannual variations of MJO composites when using the 193 RMM2 index or the 30-120 days MJO index. For clarity, only the results with the MJO index $194 O L R_{\text {filt } 90^{\circ} \mathrm{E}}$ will be presented here. Statistical significances of correlations, regression coefficients and composites are 196 calculated using the Student's t-test, taking into account effective degrees of freedom for MJO 197 composites (and their decrease when doing composites for only positive or negative IOD 198 years).

In this paper, we will examine the influence of El Niño Southern Oscillation (ENSO) 200 and Indian Ocean Dipole (IOD) on MJO variability over the Indian Ocean. We will use the 201 classical Niño3.4 $\left(120^{\circ} \mathrm{W}\right.$ to $170^{\circ} \mathrm{W}, 5^{\circ} \mathrm{N}$ to $\left.5^{\circ} \mathrm{S}\right)$ index in DJF for ENSO. For the IOD, we 202 use a new index in addition to the conventional dipole mode index (DMI, Saji et al. 1999). 203 Our index is based on OLR and is defined as the southeast $\left(80^{\circ} \mathrm{E}-100^{\circ} \mathrm{E} ; 10^{\circ} \mathrm{S}-5^{\circ} \mathrm{S}\right)$ minus 204 southwest $\left(50^{\circ} \mathrm{E}-70^{\circ} \mathrm{E} ; 5^{\circ} \mathrm{S}-0^{\circ}\right)$ OLR poles in SON. This OLR IOD index (OLR IOD) has 205 three advantages. First, OLR, a robust proxy of atmospheric deep convection and heating rate 206 in the tropics, is less subject to errors than long-term SST measurements (which rely heavily 207 on surface infra-red emission and are subject to masking by clouds; Wentz 2000). Second it is 208 available from 1974 onward whereas SST satellite observation starts in 1985. Third, this 
index based on convection is dynamically linked to the winds that force SCTR thermocline

210 variability. During SON, this OLR index is very well correlated with the conventional SST

211 DMI (0.92) and moderately with Niño3.4 SST (corr. 0.54, signif. 99.5\%). Our index is thus

212 well representative of the IOD, which is somewhat influenced by ENSO. Based on a

213 threshold of $50 \%$ of the standard deviation, there are 14 negative and 8 positive years over the

214 1974-2008 period. Tests using other threshold values, or the DMI index instead of our OLR

215 index, give qualitatively similar results.

\section{Characteristics of the two austral-summer MJO types}

Figure 1 shows spectra of OLR and SST for austral summer in the eastern Indian

Ocean. As suggested by (Saji et al., 2006), the strongest peak of convective variability is 221 observed at longer periods (55-80 day) near $8^{\circ} \mathrm{S}$, while the secondary peak is at shorter 222 periods ( $35-45$ days) and located at the equator. The SST response is also much larger at $8^{\circ} \mathrm{S}$. 223 Figure 2 a shows a zonal wavenumber-time OLR spectrum zoomed on timescales 224 corresponding to the MJO. Based on this analysis, we computed the latitudinal dependence of 225 the eastward propagating part of the OLR signal (with speed between $2.5 \mathrm{~m} / \mathrm{s}$ and $15 \mathrm{~m} / \mathrm{s}$, see 226 continuous lines on Fig. 2a) over the whole globe (Fig. 2b) and Indian Ocean (Fig. 2c). At 227 global scale, the most energetic eastward propagating convective signal during Austral 228 summer is found south of the equator, between $4^{\circ} \mathrm{S}$ and $12^{\circ} \mathrm{S}$ with a period of roughly 55 to 22990 days. Over the Indian Ocean, this signal is still the main pattern but a secondary maximum 230 is now emerging around the Equator with a period around 35-45 days.

231 In order to diagnose the spatial properties of the signals at those two timescales, and 232 determine if they are two different types of variability, we will use band-pass filtering. Even if 
233 MJO consists of episodic pulse events (Zhang 2005), this standard technique permits to 234 capture in a simple way the amplitude of MJO events separated by a characteristic period. We have selected two period bands: 35-50 days and 55-100 days bands. The choice of 236 these bands has been determined by three constraints: they (1) are centered approximately on 237 the peaks seen in Figs. 1 and 2c, (2) have the same frequency width and (3) do not overlap. 238 Hereafter in the text, we will use the name high/low frequency (HF/LF-MJO) to designate the 239 different types of MJO variability associated with these two frequency bands. We will further 240 use the abbreviations LF and HF to design the 55-100 and 35-50 days band, respectively. 241 Figure 3 shows the spatial distribution of the OLR and SST variability in those two frequency 242 bands. In agreement with figure 2, figures 3b,d suggest that HF OLR variability is 243 equatorially confined over the Indian Ocean and shifts southward only over the maritime 244 continent and western Pacific. On the other hand, the stronger LF OLR variability is clearly localized between $5^{\circ} \mathrm{S}$ and $15^{\circ} \mathrm{S}$, both in the onset region (the Indian Ocean) and further east. SST standard deviation is significantly stronger. The LF-MJO is associated with stronger OLR and wind perturbations over the SCTR and the region between Australia and Indonesia, which are characterized by a shallow and responsive mixed layer (Harrison and Vecchi, 2001, Duvel et al., 2004; Bellenger and Duvel 2007; Vialard et al., 2008, 2009). This shallowing explains probably the larger SST response there for the LF-MJO. In addition, amplitude of the SST response is also expected to grow with the timescale of forcing (Duvel and Vialard, 2007), and is thus expected to be larger for the LF-MJO type.

Figures 4 and 5 show weighted composites of SST and its diurnal amplitude (Fig. 4), OLR (Fig. 5) and surface wind, for the HF and LF-MJO. These figures illustrate the MJO patterns during the onset of convection over the Indian Ocean $\left(1^{\text {st }}\right.$ and $2^{\text {nd }}$ columns $)$ and later during its propagation toward the maritime continent $\left(3^{\text {rd }}\right.$ and $4^{\text {th }}$ columns). In the Indian 
Ocean, the HF-MJO convection onset is mostly located along the equator, whereas the LF

259 signal appears over the SCTR and maintains maximum values between $5^{\circ} \mathrm{S}$ and $10^{\circ} \mathrm{S}$ during 260 its eastward propagation (Fig. 5). For both types, the lead-lag relation between OLR and SST 261 is similar to previous studies (see review of Waliser 2005); warm SST anomalies follow/lead 262 MJO inactive/active phase by about a quarter of period. However, the oceanic response 263 related to the LF type is much stronger than that related to HF type, with warm SST 264 anomalies exceeding $0.2^{\circ} \mathrm{C}$ over a large domain and important anomalies of SST diurnal 265 amplitude over the southern Indian Ocean ( $1^{\text {st }}$ and $2^{\text {nd }}$ columns in Fig. 4).

Farther east, the oceanic signature of MJO propagation is also different for the two timescales $\left(3^{\text {rd }}\right.$ and $4^{\text {th }}$ columns in Fig. 4$)$. Within the maritime continent, warmer SST with a larger diurnal cycle is observed for the LF-MJO component before the passage of MJO active phase. Interestingly, convection (as well as precipitation, not shown) anomalies over north Australia are significantly stronger for the LF-MJO, suggesting that this LF type has a greater impact on North Australian weather than the HF one.

\section{Interannual variations of the austral-summer MJO types}

Previous studies (e.g. Harrison and Vecchi 2001, Duvel et al. 2004, Saji et al. 2006, Duvel and Vialard 2007, Vialard et al 2008, 2009) have suggested that interannual variability of the oceanic stratification could modulate the SST signature of the MJO and even maybe the MJO itself. In this section, we will investigate the LF and HF-MJO types interannual variability. The interannual variations of the activity of each of the two MJO types in austral

280 MJO types tend to occur independently from one another.

\subsection{Interannual modulation of LF-MJO activity}


To understand what can modulate LF-MJO, Figure 6 shows interannual surface 283 atmospheric and oceanic anomalies during the boreal winter (DJFM in Figs 6c,d) and the 284 preceding fall (SON in Figs 6a,b) regressed on the amplitude of the LFMJO activity during 285 the boreal winter. The clearest signal for the regressed variables in DJFM is in the sea-level anomaly (SLA, Fig. 6c), with negatives values in the SCTR associated with an intensification

287 of the LF type. Similar results are obtained over a longer period when using SLA from 288 various oceanic re-analysis products. The same analysis for SST, OLR and surface wind in 289 boreal winter show small amplitude signals in the Indian Ocean, and do not seem to be 290 strongly associated with LF-MJO interannual variability (not shown). Other papers (e.g. 291 Vecchi and Harrison, 2001; Duvel et al. 2004) had already proposed that thermocline changes 292 in the SCTR could increase or diminish the amplitude of the SST signature associated with 293 the MJO. Observed interannual variations of the DJFM intraseasonal SST variability in $60^{\circ} \mathrm{E}-$ 294 $90^{\circ} \mathrm{E}, 8^{\circ} \mathrm{S}-3^{\circ} \mathrm{S}$ are indeed anti-correlated (-0.60, significant at the $99 \%$ confidence level) with 295 mean DJFM SLA along the thermocline ridge. The present paper shows that, in addition, the amplitude of the LF-MJO type itself varies interannually with the amplitude of LF SST 297 variability (see fig. 6d and first column of Table 1) and with the thermocline depth variability 298 in the SCTR region (Fig. 6c).

The origin of the sea-level anomaly seen in figure $6 \mathrm{c}$ can easily be traced back to ocean300 atmosphere conditions in preceding September-November (SON). The wind, SST and OLR 301 pattern in SON is consistent with a negative phase of the IOD. Negative IOD are known to 302 force off-equatorial Rossby upwelling waves propagating slowly toward the south-west 303 Indian Ocean and generating the negative sea-level anomaly seen in Fig. 6c (Masumoto and 304 Meyers, 1998; Xie et al., 2002; Rao and Behera, 2005; Vialard et al., 2009). Figures 6a and $3056 \mathrm{~b}$ show that negative IOD tend to occur during fall (SON) that precede winters with strong 306 LF-MJO activity. There tends to be a phase locking of IOD events to El Niño events (Gualdi 
et al. 2003, Yamagata et al. 2004). Hence, maps similar to figure 6a,b,c show a typical La

308 Niña pattern in the Pacific Ocean (not shown). To isolate which of the IOD or ENSO does mostly influence the LF-MJO type, partial correlations for different pairs were computed

310 (Table 1). Even if the LF-MJO is correlated with Niño3.4 SST, it is IOD variability (see 311 definition of the index in section 2) rather than ENSO that explains most of the variance of 312 the southern low-frequency MJO.

\section{$313 \quad 4.2$ Impact of IOD on HF-MJO and LF-MJO}

314 In the rest of the section, we will assess systematically the impact of IOD on the LF and 315 HF MJO types. To that end, we will use the IOD index described in section 2. We first 316 perform analyses similar to Figs. 1, 2 and 4 separately for positive and negative IOD years.

\subsubsection{Modulation of SST and OLR intraseasonal variability by IOD}

Fig. 7 shows the changes in SST and OLR spectrum after a negative or positive IOD year. At the equator, the SST spectrum is not significantly changed. On the other hand, there is a clear increase of OLR equatorial variability at lower frequencies after negative IOD years. At $8^{\circ} \mathrm{S}$, there is an increase of intraseasonal SST variability in the SCTR following negative IODs. This again confirms what was hypothesized by several previous studies (e.g. Vecchi and Harrison, 2001; Duvel et al. 2004): a thinner SCTR thermocline favours a local increase of SST intraseasonal variability (cf. their significant correlation of 0.60 shown previously in section 4.1). Second, there is also an increase in OLR LF variability following a negative IOD

326 (Figure $7 \mathrm{~b}$ ). This increase is almost within the range of uncertainty, but fig. 6a,b shows that 327 the negative relationship between LF-MJO, estimated with the simpler method using band328 pass filtering, and IOD is significant.

\subsubsection{Latitudinal-frequency distribution modulated by IOD}

Figure 8 (similar to Fig. 2 but after positive/negative IOD years) shows changes in the

331 eastward-propagating components of OLR. Over the globe (left and middle panels), the OLR 
eastward-propagating signal is stronger after negative IOD years, with a maximum at LF (Fig.

333 8d). In the Indian Ocean, the differences are the strongest with a clear unique peak at LF 334 centered on $8^{\circ} \mathrm{S}$ after negative IOD years. After positive IOD years, there are two spectral 335 peaks. The $8^{\circ} \mathrm{S}$ LF peak remains, but is weaker than after negative IOD years. But another 336 peak at HF appears at the equator. The HF-MJO type" is much better defined after positive 337 IOD years and quasi-inexistent after negative IOD years.

\subsection{3 spatial patterns of MJO composites}

Figure 9 (cf. figures 4 and 5) shows the changes in the HF and LF types following a positive or negative IOD. The MJO index used to produce figs 9 and 10 is the $30-120$ days one, so that MJO period is not constrained a priori. Hence the difference in latitude and period respectively obtained eventually in Figs 9 and 10 can thus only originate from the different intrinsic periods of MJO events after positive and negative IOD. After positive IOD years, an equatorial MJO onset with symmetric patterns similar to the HF-MJO type described in section 3 seems to be favoured. On the other hand, after negative IOD years (and also to some extent after neutral IOD conditions, not shown), the patterns are similar to those

347 of the LF-MJO southern type: stronger SST signature with enhanced warming (cooling) 348 during MJO break (active) phase, stronger diurnal cycle signal and maximum wind and OLR anomaly shifted to the south.

\subsubsection{Propagation: extent and speed}

Figure 10 finally illustrates the impact of IOD (and ENSO) on the propagation 352 characteristics of the MJO. Time-longitude $\left(15^{\circ} \mathrm{S}-5^{\circ} \mathrm{N}\right)$ diagrams of lagged weighted 353 composites are plotted for positive/negative IOD. The MJO OLR signal is stronger and 354 propagates further eastward (to the date line) after negative IOD events than after positive 355 ones. The difference in MJO timescales shown previously through spectral analyses (Figs. 7 356 and 8) is also evident in Fig. 10, especially in the Indian Ocean, with a shorter/longer 
$357(\sim 30 / 60)$ days period between two successive non-active phases after positive/negative IOD

358 (due to the pulse" nature of the MJO convective event (e.g. Zhang, 2005), these periods 359 should be somewhat shorter than the ones between two active phases). So as to better 360 differenciate the southern LF-MJO, stronger after negative IOD, from the equatorial HF-MJO, 361 stronger after positive IOD, Hovmullers with thinner latitudinal widths of $5^{\circ}$ were computed. 362 Slower propagation speeds in the ITCZ/SPCZ are observed for the southern $\left(12^{\circ} \mathrm{S}-7^{\circ} \mathrm{S}\right) \mathrm{MJO}$ 363 after negative IOD $(\sim 4.5 \mathrm{~m} / \mathrm{s})$ compared to the equatorial $\mathrm{MJO}\left(2.5^{\circ} \mathrm{S}-2.5^{\circ} \mathrm{N}\right)$ after positive 364 IOD $(\sim 6.5 \mathrm{~m} / \mathrm{s})$, for the active as well as for the non-active phases (not shown). MJO event 365 after negative IOD tends to be to the south and to have asymmetric circulation anomalies. The 366 asymmetry weakens low-level frictional convergence/divergence processes and could be at 367 the origin of MJO slowdown [Salby et al. 1994]. This issue requires further studies. To 368 conclude this time-longitude analysis, the longer longitudinal pathway in the ITCZ/SPCZ 369 (and slower speed) of MJO events after negative IOD could possibly explain the increase in 370 MJO period.

This section has shown a strong relationship between Indo-Pacific interannual 372 anomalies of the ocean-atmosphere system during the boreal fall of a particular year and 373 characteristics of the MJO during the following winter. We have been able to separate the two 374 MJO types without any help of temporal filter, in contrast to Section 3. This separation 375 suggests that the two MJO types evidenced here are not the result of an artifact related to the 376 filtering method and that they represent two physically distinct MJO types. It also suggests 377 that the southern LF and equatorial HF MJO types do not simply correspond to the MJO in 378 austral summer and equinoxial seasons respectively. 


\section{Summary and Discussion}

In this final section, we will first summarize the results of this paper, then propose two

main hypotheses for the processes explaining the interannual variations of the LF/HF-MJO types, and finally discuss physical mechanisms possibly involved in the LF-MJO type.

\subsection{Summary}

In the present paper, we have used observations to describe oceanic and atmospheric signals associated with the Madden-Julian oscillation in austral summer. The MJO can be broadly defined as eastward-propagating, convective signals in the 30-100 days range. The current analysis suggests that there are in fact two separate spectral peaks within the 35-50 days and 55-100 days band, with different properties, which we named the high-frequency (HF) and low-frequency (LF) austral-summer MJOs. The LF-MJO is maximum under the ITCZ, at around $8^{\circ} \mathrm{S}$ and has a clear oceanic signature, in both SST and amplitude of the SST diurnal cycle. The HF-MJO is centered on the equator, and has a significantly weaker oceanic signature, despite roughly equivalent amplitudes of the atmospheric perturbations. These two MJO types have a clear interannual amplitude variability that can be related to the IOD (and concurrent ENSO). The LF-MJO and the index that we use in this study are more directly

396 related to the IOD than to ENSO (Table 1), suggesting that the IOD has the largest influence. 397 After a negative IOD, the HF-MJO type is almost non-existent (whereas it is rather strong 398 after a positive IOD). On the other hand, the LF-MJO type shows increased variability in both 399 atmospheric convection and oceanic responses after a negative IOD, with a propagation 400 extending further east, having potentially a stronger impact on Australian and south-west 401 Pacific weather variability. In the following subsection, we will propose two main hypotheses that could explain some of the observed statistics that we presented in this paper. 


\subsection{Discussion on interannual variations: physical hypotheses}

404

405

406

407

408

409

410

411

412

413

414

415

416

417

418

419

420

421

422

423

424

425

426

427

\subsubsection{Importance of the background state}

The first and most straightforward physical hypothesis is that the mean state of the atmosphere is directly influencing the properties of the MJO type that can develop. Figure 11 shows some variables illustrating the state of the ocean-atmosphere system in DJFM after positive and negative IOD events, which characterize the two different states over which MJOs develop. This figure shows patterns both characteristic of the IOD and ENSO (they tend to co-occur, although not systematically). The changes in mean state could explain some of the results of this study. For example, the low-level westerlies and convection / rainfall from south-eastern Indian Ocean to western Pacific are stronger after a negative IOD than after a positive one (Fig. 11a), and both provide a favourable ground for MJO propagation (Inness and Slingo 2003; Zhang and Dong 2004; Watterson and Syktus 2007). Furthermore, as negative IOD seem to favour a southward MJO onset and propagation, this southern shift could allow the MJO to be less perturbed by the lands of the maritime continent, and to propagate further east. All these processes could explain why, after negative IOD, MJO tends to be globally stronger and to propagate more to the south and further east in a more active SPCZ, having hence a longer (and slower) pathway. The latter could in turn explain the longer period/lower frequency tendency of the MJO after negative IOD events (rather than the contrary). Also, the equatorial HF-MJO type might be an expression of interaction between linear equatorial atmospheric dynamics and convection, and as such be favoured during years when there is convection along the equator in the Indian Ocean, i.e. more after positive IOD. On the other hand, when considering the atmospheric background properties over the SCTR region after a negative IOD, the observed significant changes cannot explain why the MJO tends to onset over the SCTR: westerlies are weaker (figures 11af), convection is decreased (figures $11 \mathrm{bg}$ ) and the surface is colder (figures $11 \mathrm{ch}$ ) over the SCTR after a negative IOD. 
428 The processes of how the atmospheric background state might be responsible for the increased LF-MJO remain to be investigated against existing MJO theories.

\subsubsection{Importance of ocean-atmosphere coupling}

The other possibility is that, as suggested by many studies, coupling with the ocean is important for the properties of the MJO, for its onset and for its eastward propagation (e.g. Waliser et al. 1999; Inness and Slingo 2003; Maloney and Sobel 2004; Zhang et al. 2005). Some studies also proposed (e.g. Woolnough et al., 2007) that a good description of the diurnal cycle modulation associated with the MJO is needed to improve MJO description and forecasts.

Here, larger intraseasonal SST responses are observed for the LF-MJO type, suggesting that coupling could play a stronger role for LF-MJO than for HF-MJO. We have shown, as suggested by other previous studies (e.g. Duvel et al. 2004), that the SST response to the MJO was stronger after negative IOD events. This increased sensitivity has been explained by previous studies: a negative IOD forces upwelling Rossby waves in the $5^{\circ}-10^{\circ} \mathrm{S}$ band in the eastern and central Indian Ocean, which later raise the thermocline in the SCTR region. This raised thermocline modulates the mixed layer depth and hence the reactivity of the SST to airsea fluxes (Duvel et al. 2004), but also the amount of entrainment / upwelling into the mixed layer (Lloyd and Vecchi, 2009; Vinayachandran and Saji, 2008; Resplandy et al., 2009), resulting in stronger SST response to the LF-MJO after a negative IOD in the SCTR, which is also the breeding ground for MJO onset.

Extending these results, we also show here that the amplitude of the LF-MJO itself is increased following negative IOD years, (and is significantly correlated to increased amplitude of LF SST variability over the SCTR). While this LF-MJO increase could be explained by changes of the atmospheric mean state, and could explain the increased LF SST variability, the other alternative is that the larger oceanic response after the negative IOD 
453 years in the SCTR favours larger amplitude of the southern LF-MJO, as suggested by Duvel 454 et al. (2004). We also observe here that the MJO modulation of the diurnal cycle seemed 455 stronger ${ }^{2}$, possibly partly because the reduced mean westerlies and cloud cover after IOD 456 could favour the occurrence of diurnal warm layers. This enhancement of SST diurnal cycle 457 modulation by the MJO could also enhance SST intraseasonal variability and air-sea coupling 458 in this region, hence favouring the southern MJO onset at the end of negative IOD events. To 459 summarize, these two processes - thinner MLD and increased SST diurnal cycle - can 460 promote local MJO onset along the SCTR (even if the mean DJFM ITCZ is weaker and mean 461 SST is colder in the region).

However, how air-sea coupling might modify the properties of the LF-MJO 463 downstream of the SCTR region is unclear. The region between Australia and Indonesia has 464 large SST intraseasonal variability (e.g. Duvel and Vialard 2007) and a shallow MLD 465 (Bellenger and Duvel 2007). But the interannual modulation of the SST intraseasonal 466 variability in this region has not been studied. In the western Pacific, the SST intraseasonal 467 variability in response to the MJO is much smaller (Duvel and Vialard 2007), and the 468 thermocline is deep, providing no obvious mechanism of control of the SST intraseasonal 469 variability by lower frequencies. Whether interannual modulation of air-sea coupling in the 470 SCTR region is enough to modify the properties of the MJO downstream to the western 471 Pacific thus remains to be investigated more thoroughly.

It is quite difficult to assess from observations only the relative importance of the 474 processes mentioned above (i.e. atmospheric background and/or ocean-atmosphere coupling) 475 in setting the properties of the HF and LF austral summer MJO types. On the other hand,

\footnotetext{
2 The composites being however rather noisy because of observational uncertainties, this study suggests the need for further studies, when more accurate long-term observations will be available
} 
these hypotheses could be tested in general circulation models with the observational analyses

477 proposed here as a benchmark. In a follow-on study, we will partly follow that objective, 478 using a coupled general circulation model, which is able to resolve the SST diurnal cycle.

479 To conclude, the present study highlights important scale interactions and emphasizes 480 the necessity to implement ocean-atmosphere observing/modeling systems for the entire 481 tropical Indian Ocean, including its southern part, with sufficient vertical and temporal 482 resolution. The ability to predict the MJO and its global impacts will depend not only on the 483 knowledge of large-scale conditions, but also on an accurate estimate of the Indian Ocean 484 variability on a regional scale.

486 Acknowledgments. The authors would like to thank JAMSTEC, especially FRCGC and the 487 Earth Simulator Center, for their great hospitality and the high performance material and 488 computer facilities they offer. Dr. Sophie Cravatte, Dr. Fabien Durand, and all the LEGOS 489 and LOCEAN teams are greatly thanked for their support of this research project. Most of the 490 observations data were made available mainly by NOAA/NCEP/CPC through Climate 491 Diagnostics Center (CDC), IRI/LDEO Climate Data Library and AVISO servers. AVHRR 492 Pathfinder SST is NODC/NOAA. QuikScat data are produced by Remote Sensing Systems 493 and sponsored by the NASA Ocean Vector Winds Science Team. Those data were obtained 494 from the IFREMER (CERSAT) ftp server. The authors also wish to acknowledge the use of 495 NOAA/PMEL Ferret program for analysis and graphics in this paper. The Japan Society for 496 the Promotion of Science (JSPS) and the French Research Agency (ANR, Project INLOES) 497 funded this work. 


\section{REFERENCES}

500 Atlas R., R. N. Hoffman, S. C. Bloom, J. C. Jusem, and J. Ardizzone, 1996: A Multiyear

501

502

503

504

Global Surface Wind Velocity Dataset Using SSM/I Wind Observations. Bull. Amer. Meteor. Soc., 77, 869-882.

Bellenger, H. and J.P. Duvel, 2007: Intraseasonal Convective Perturbations related to the Seasonal March of the Indo-Pacific Monsoons, Journal of Climate, 20, 2853-2863.

Bentamy A., Y. Quilfen, F. Gohin, N. Grima, M. Lenaour and J. Servain, 1996: Determination and validation of average wind fields from ERS-1 scatterometer measurements. The Global Atmosphere and Ocean System, 4, 1-29.

Bernie, D. J., S. J. Woolnough, J. M. Slingo and E. Guilyardi, 2005: Modeling of diurnal and intraseasonal variability of the ocean mixed layer. J. Climate, 18, 1190-1202.

Bernie D.J., Guilyardi E., Madec G., Woolnough S.J., Slingo J.M., 2007: Impact of resolving the diurnal cycle in an ocean-atmosphere GCM. Part 1: Diurnally forced OGCM. Clim Dyn $29: 575-590$

Bernie, D. J.; Guilyardi, E.; Madec, G.; Slingo, J. M.; Woolnough, S. J.; Cole, J., 2008: Impact of resolving the diurnal cycle in an ocean atmosphere GCM. Part 2: A diurnally coupled CGCM. Climate Dynamics, 31, 909-925.

Charney, J. G., and A. Eliassen, 1964: On the growth of the hurricane depression. J. Atmos. Sci., 21, 68-75.

Daget, N., Weaver, A. T. and M. A. Balmaseda, 2008: An ensemble three-dimensional variational data assimilation system for the global ocean: sensitivity to the observationand background-error formulation. ECMWF Tech. Memo. No. 562.

Duvel, J. P., and J. Vialard, 2007: Indo-Pacific sea surface temperature perturbations associated with intraseasonal oscillations of the tropical convection, J. Climate, 20, 30563082. 
Duvel, J.P., R. Roca and J. Vialard, 2004: Ocean mixed layer temperature variations induced by intraseasonal convective perturbations over the Indian Ocean. J. Atm. Sciences, 61 , 1004-1023.

Gill, A. E., 1980: Some simple solutions for heat-induced tropical circulation. Q. J. R. Meteorol. Soc. 106, 447-462.

Godfrey, J. S., R. A. Houze, Jr., R. H. Johnson, R. Lukas, J.-L. Redelsperger, A. Sumi, and R. Weller, 1998: Coupled Ocean-Atmosphere Response Experiment (COARE): An interim report. J. Geophys. Res., 103, 14,395-14,450.

Goodberlet, M.A., C.T. Swift, and J.C. Wilkerson, 1989: Remote Sensing of Ocean Surface Winds with the Special Sensor Microwave Imager. J. Geophys. Res., 94, 14544-14555.

Harrison, D. E., and G.A. Vecchi, 2001: January 1999 Indian Ocean cooling event. Geophys. Res. Lett., 28, 3717-3720.

Hendon, H. H., 2000: Impact of air-sea coupling on the Madden-Julian Oscillation in a general circulation model. J. Atmos. Sci., 57, 3939- 3952.

Hendon H. H., 2005: Air-sea interaction, in Intraseasonal variability of the Ocean Atmosphere Climate System, edited by W.K.M. Lau and D.E. Waliser, Springer, Heidelberg, Germany.

Hermes, J.C. and C.J.C. Reason, 2008: Annual cycle of the South Indian Ocean (SeychellesChagos) thermocline ridge in a regional ocean model, J. Geophys. Res., 113, C04035, doi:10.1029/2007JC004363.

Inness, P. M., and J. M. Slingo 2003: Simulation of the Madden-Julian Oscillation in a coupled general circulation model. Part I: Comparisons with observations and an atmosphere-only GCM, J. Clim., 16, 345-364.

Kanamitsu, M., Ebisuzaki, W., Woollen, J., Yang, S.-K., Hnilo, J. J., Fiorino, M., and Potter, G. L., 2002: NCEP-DOE AMIP-II reanalysis. Bull. Amer. Meteor. Soc., 1631-1643. 
Kawai Y. and Wada A., 2007: Diurnal sea surface temperature variation and its impact on the atmosphere and ocean: A review. Journal of Oceanography 63(5): 721.

551 Liebmann, B., and C. A. Smith, 1996: Description of a complete (interpolated) outgoing 552 longwave radiation dataset. Bull. Amer. Meteor. Soc., 77, 1275-1277.

553 Llyod I.D. and G.A. Vecchi, 2009: Submonthly Indian Ocean cooling events and their 554 relation to large-scale conditions. J. Geophys. Res., submitted.

555 Madden, R. A., and P. R. Julian, 1994: Observations of the 40-50- day tropical oscillation556 A review. Mon. Wea. Rev., 122, 814-836.

557 Maloney E.D. and A.H. Sobel 2004: Surface fluxes and ocean coupling in the tropical 558 intraseasonal oscillation. Journal of Climate, 17, 4368-4386.

559 Masumoto, Y. and G. Meyers, 1998: Forced Rossby waves in the southern tropical Indian 560 Ocean, J. Geophys. Res. (Oceans), 103, 27589-27602.

561 Matthews, A. J., 2000: Propagating mechanism for the Madden Julian oscillation. Quart. J. Roy. Met. Soc., 126, 2637-2651.

563 Rao, S.A., and S. K. Behera 2005: Subsurface influence on SST in the tropical Indian Ocean: 564 structure and interannual variability. Dyn. Atmos. Ocean. ,39, 103-135.

565 Resplandy L., J. Vialard, M. Lévy, O. Aumont and Y. Dandonneau 2009 : Seasonal and 566 intraseasonal biogeochemical variability in the thermocline ridge of the Indian Ocean. $J$. 567 Geophys. Res., submitted.

568 Reverdin, G., D. Cadet and D. Gutzler, 1986. Interannual displacements of convection and 569 surface circulation over the equatorial Indian Ocean. Quarterly Journal of the Royal $570 \quad$ Meteorological Society 112, 43-46.

571 Reynolds, R. W., N. A. Rayner, T.M. Smith, D. C. Stokes and W. Wang, 2002: An improved 572 in situ and satellite SST analysis for climate. J. Climate, 15, 1609-1625. 
573 Saji, N. H., B. N. Goswami, P. N. Vinayachandran and T. Yamagata, 1999: A dipole mode in 574 the tropical Indian Ocean. Nature, 401, 360-363.

575 Saji, N.H., S.-P. Xie, and C. -Y. Tam, 2006: Satellite observations of intense intraseasonal 576 cooling events in the tropical south Indian Ocean. Geophys. Res. Lett., 33, L14704, doi: $577 \quad 10.1029 / 2006 G L 026525$.

578 Salby, M. L., R. R. Garcia, and H. H. Hendon, 1994: Planetary scale circulations in the 579 presence of climatological and wave induced heating. J. Atmos. Sci., 51, 2344-2367.

580 Smith, T. M., and R. W. Reynolds, 2004: Improved extended reconstruction of SST (1854581 1997). J. Clim., 17, 2466-2477.

582 Stuart-Menteth, A. C., I. S. Robinson and P. G. Challenor, 2003: A global study of diurnal 583 warming using satellite derived sea surface temperature. J. Geophys. Res., 108(C5), 3155, 584 doi:10.1029/2002JC001534.

585 Takayabu, Y. N., 1994: Large-scale cloud disturbances associated with equatorial waves. Part 586 I: Spectral features of the cloud disturbances. J. Meteor. Soc. Japan, 72, 433- 448.

587 Vialard, J., J-P. Duvel, M. McPhaden, P. Bouruet-Aubertot, B. Ward, E. Key, D. Bourras, R.

588 Weller, P. Minnett, A. Weill, C. Cassou, L. Eymard, T. Fristedt, C. Basdevant, Y.

589 Dandoneau, O. Duteil, T. Izumo, C. de Boyer Montégut, S. Masson, F. Marsac, C.

590 Menkes, S. Kennan, 2009, Cirene: Air Sea Interactions in the Seychelles-Chagos

591 thermocline ridge region, Bull. Am. Met. Soc., in press.

592 Vialard, J., G. Foltz, M. McPhaden, J.-P. Duvel, and C. de Boyer Montegut, 2008: Strong 593 Indian Ocean cooling associated with the Madden-Julian Oscillation in late 2007 and early 594 2008. Geophys. Res. Lett., 35, L19608, doi:10.1029/2008GL035238.

595 Vinayachandran, P. N., and N. H. Saji, 2008: Mechanisms of South Indian Ocean 596 intraseasonal cooling. Geophys. Res. Lett., 35, L23607, doi:10.1029/2008GL035733. 
Waliser, D. E., K. M. Lau, J.-H. Kim, 1999: The influence of coupled Sea Surface Temperatures on the Madden-Julian oscillation: A model perturbation experiment. $J$. Atmos. Sci., 56, 333-358.

Waliser, D. E., 2005: Intraseasonal Variability, in The Asian Monsoon, edited by B. Wang, p. 844 Springer, Heidelberg, Germany.

Wang, B., 1988: Dynamics of tropical low-frequency waves: An analysis of the moist Kelvin wave, J. Atmos. Sci., 45, 2051-2065.

Watterson I.G., Syktus J., 2007: The influence of air-sea interaction on the Madden-Julian Oscillation: the role of the seasonal mean state. Climate Dynamics 28(7-8): 703.

Weaver, A. T., Deltel, C., Machu, E., Ricci, S. and N. Daget, 2005: A multivariate balance operator for variational ocean data assimilation. Q. J. Roy. Meteorol. Soc., 131, 3605-3625. Webster, P. J., A. M. Moore, J. P. Loschnigg, and R. R. Leben, 1999: Coupled oceanicatmospheric dynamics in the Indian Ocean during 1997-98. Nature, 401, 356-360.

Wentz, F.J., C. Gentemann, D. Smith, and D. Chelton (2000) Satellite Measurements of Sea Surface Temperature Through Clouds. Science 288 (5467), 847.

Wheeler, M., and G.N. Kiladis, 1999: Convectively coupled equatorial waves: Analysis of clouds and temperature in the wavenumber-frequency domain. J. Atmos. Sci., 56, 374-399. Wheeler, M.C., and H.H. Hendon, 2004: An all-season real-time multivariate MJO Index: Development of an index for monitoring and prediction. Mon. Wea. Rev., 132, 1917-1932.

Woolnough, S. J., F. Vitart, and M. A. Balmaseda, 2007: The role of the ocean in the Madden-Julian Oscillation: Implications for MJO prediction. Q. J. R. Meteorol. Soc., 133, $622,117-128$

Xie, S.-P., H. Annamalai, F.A. Schott and J.P. McCreary, 2002: Structure and mechanisms of south Indian climate variability, J. Climate, 9, 840-858.

Yamagata, T., S. K. Behera, J.-J. Luo, S. Masson, M. Jury, and S. A. Rao, 2004: Coupled 

ocean-atmosphere variability in the tropical Indian Ocean, in Earth Climate: The OceanAtmosphere Interaction, Geophys. Monogr. Ser., 147, edited by C. Wang, S.-P. Xie, and J. A. Carton, pp. 189-212, AGU, Washington, D. C.

625 Yasunaga K, Fujita M, Ushiyama T, Yoneyama K, Takayabu Y.N. ,Yoshizaki M., 2008: 626 Diurnal Variations in Precipitable Water Observed by Shipborne GPS over the Tropical 627 Indian Ocean. SOLA 4: 97.

628 Yokoi, T., T. Tozuka, and T. Yamagata, 2008: Seasonal variation of the Seychelles Dome. J. $629 \quad$ Climate, 21, 3740-3754.

630 Zhang C., Dong M., 2004 Seasonality in the Madden-Julian oscillation. J Climate 17:3169$631 \quad 3180$.

632 Zhang, C., 2005: Madden-Julian Oscillation, Rev. Geophys., 43, RG2003, 633 doi:10.1029/2004RG000158.

634 Zhang, C, M. Dong, H. H. Hendon, E. D. Maloney, A. Marshall, K. R. Sperber, and W. 635 Wang, 2005: Simulations of the Madden-Julian Oscillation in Four Pairs of Coupled and 636 Uncoupled Global Models. Climate Dynamics, DOI: 10.1007/s00382-006-0148-2. 
Table 1. First column: correlations of the standard deviation of LF OLR (DJFM, $55^{\circ} \mathrm{E}-165^{\circ} \mathrm{E}$, $\left.64110^{\circ} \mathrm{S}-0^{\circ}\right)$ with previous SON OLR_IOD, DMI, Niño3.4 SST over 1979-2008, and with the 642 standard deviation of low-freq. SST in DJFM over the SCTR $\left(60^{\circ} \mathrm{E}-90^{\circ} \mathrm{E}, 8^{\circ} \mathrm{S}-3^{\circ} \mathrm{S}\right)$ from TMI 643 (1998-2007)/Reynolds (1985-2007). Second to fourth column: partial correlations for 644 different pairs, evidencing that rather than ENSO, it is OLR_IOD variability (and to a less extent the DMI) that explains most of the variance of the southern low-frequency MJO.

646

Fig. 1: Spectra (in amplitude) for $\operatorname{SST}\left({ }^{\circ} \mathrm{C}\right.$ day, left $)$ and $\mathrm{OLR}\left(\mathrm{W} \mathrm{m}^{-2}\right.$ day, right $)$ along the thermocline ridge (at $8^{\circ} \mathrm{S}$; continuous black lines) and along the equator (dashed black lines) in NDJFM in the Indian Ocean (spectral amplitudes averaged over $\left.60^{\circ} \mathrm{E}-90^{\circ} \mathrm{E}\right)$. The vertical/horizontal lines on the right panel show the low and high frequency bands selected (55-100 days and 35-50 days). Light blue lines show the intervals confident at the $90 \%$ level. To reduce windowing effect, the component of the signal with periods greater than 125 days was removed before computing the spectra.

654

Fig. 2: (a) OLR spectrum (in amplitude, global, $10^{\circ} \mathrm{S}-5^{\circ} \mathrm{N}$ mean) ; (b,c) latitudinal distribution of OLR eastward propagating component (global in (b) and Indian Ocean only $\left(55^{\circ} \mathrm{E}-95^{\circ} \mathrm{E}\right)$ in (c) ) in austral summer (NDJFM). In (a), the $\mathrm{x}(\mathrm{y})$-axis is zonal wave number (period). The dashed line represents the conventional MJO speed $(5 \mathrm{~m} / \mathrm{s})$. In $(\mathrm{b}, \mathrm{c})$, the eastward propagating signal has been calculated by averaging spectrum over positive zonal wave numbers between

660 the two continuous diagonal lines shown in (a) (i.e. between $2.5 \mathrm{~m} / \mathrm{s}$ and $15 \mathrm{~m} / \mathrm{s}$ speeds). In

661 (b,c), the $\mathrm{x}(\mathrm{y})$-axis is the period (latitude). The vertical/horizontal lines on the right panel

662 show the LF and HF bands. Unit is in $\mathrm{W} \mathrm{m}^{-2}$ day. 
664 Fig. 3: maps of standard deviations of SST (TMI, left column; ${ }^{\circ} \mathrm{C}$ ) and OLR (right column;

$665 \mathrm{~W} \mathrm{~m}^{-2}$ ) for MJO HF (upper row) and LF (lower row) bands in DJFM.

666

667 Fig. 4: difference between the HF (upper row) and LF (lower row) MJO composites, for SST 668 diurnal amplitudes and daily SST, firstly prior to MJO onset in the Indian Ocean (left 669 columns) and secondly prior to MJO propagation over the maritime continent (right columns).

670 The weighted composites are at different lags for a negative intraseasonal OLR at $90^{\circ} \mathrm{E}$, $67110^{\circ} \mathrm{N}-10^{\circ} \mathrm{S}$ (location indicated by the black vertical bars) at $\mathrm{t}=0$ in DJFM. SST diurnal 672 amplitude and daily SST are shown about a quarter to eighter period before the OLR 673 composites of figure 5. Surface winds are plotted for significance higher than $85 \%$. Black 674 contours show the $95 \%$ significant level.

675

676 Fig. 5: similar to figure 4, but for OLR composites only, at various lags.

678 Fig. 6: ocean and atmosphere background state in boreal fall (SON) and winter (DJFM) 679 regressed on southern LF-MJO activity in DJFM (OLR 55-100days, $\left.55^{\circ} \mathrm{E}-165^{\circ} \mathrm{E} ; 10^{\circ} \mathrm{S}-0^{\circ}\right)$. 680 (a): mean SST $\left({ }^{\circ} \mathrm{C}, 1974-2007\right)$ and wind stress $\left(\mathrm{N} \mathrm{m}^{-2}, 1987-2007\right)$ in fall (SON) before 681 strong low-frequency MJO. (b): same as (a) but for OLR (color, W m², 1974-2007). (c): for 682 mean SLA in DJFM (cm, AVISO, 1992-2007). (d): for standard deviation of low-frequency 683 SST in DJFM (TMI, 1998-2007). Surface winds are plotted for significance higher than 90\%. 684 The 90\% significant level is added in black contours. The boxes defining the OLR-IOD index 685 are shown in (b).

686

687 Fig. 7: same as Fig. 1, but for boreal winters following negative (black) and positive (red) 
IOD in fall.

689

690 Fig. 8: longitude-time spectrum (left column), and latitudinal distribution of eastward

691 propagating component globally (middle column) and in the Indian Ocean (right column), for 692 OLR in DJFM, after positive IOD (upper row) and negative IOD (lower row) in SON (similar 693 method to Fig. 2).

694

Fig. 9: MJO weighted composites in winter after positive (upper row) and negative (lower row) IOD conditions in fall: for SST ( $2^{\text {nd }}$ column) and OLR ( $3^{\text {rd }}$ column $)$ intraseasonal anomalies during MJO onset, and for intraseasonal SST just after the passage of MJO active phase $\left(4^{\text {th }}\right.$ column $)$, in DJFM. Surface winds are plotted for significance higher than $85 \%$. The $90 \%$ significant level is added in black contours. In the first column, the difference of the $\mathrm{t}=-$ 20days and $\mathrm{t}=0$ composites for the diurnal amplitude of SST (its total anomaly, no intraseasonal filtering) is plotted to remove the strong interannual signal (cf. fig. 11e,j), as the latter can not be trivially removed otherwise due to missing data constraints. The MJO index used here has been filtered in the broad 30-120days band, so as to let MJO timescale unconstrained a priori (see text for details).

Fig. 10: time-longitude diagrams for lag-composites of OLR (color, to show MJO slow propagation in Indo-Pacific ITCZ-SPCZ) and SLP (contour, to evidence the circum-equatorial 708 propagation as faster moist Kelvin waves), following different IOD conditions in fall: positive 709 (upper) and negative (lower). The diagonal line shows the conventional MJO speed (5m/s). 710 Latitudinal averaging is done over $15^{\circ} \mathrm{S}-5^{\circ} \mathrm{N}$ to capture the average propagation of MJO 711 convection, shifted to the south during boreal winter. The fields composited here have not 712 been high-pass filtered to limit time-aliasing. The MJO index used here is filtered over the 
713 broad 30-120days band, as in Fig. 9.

714

715 Fig. 11: Composites of mean DJFM state after positive (left column) and negative (right

716 column) IOD. $1^{\text {st }}$ line: zonal wind stress (SSMI/ERS1-2/Quikscat; N/m²), $2^{\text {nd }}$ line:

717 precipitation $(\mathrm{mm} / \mathrm{d}, \mathrm{GPCP}), 3^{\text {rd }}$ line: SST $\left({ }^{\circ} \mathrm{C}\right.$, ERSST/Reynolds $), 4^{\text {th }}$ line: ocean mixed layer

718 (m, from CERFACS-ENSEMBLES ocean reanalysis), $5^{\text {th }}$ line: amplitude of SST diurnal

719 cycle ( ${ }^{\circ} \mathrm{C}$, AVHRR). 7 (14) positive (negative) IOD events were used for the longest time

720 series (1974-2007, SST, OLR and MLD). However, the shortest record (SST diurnal cycle)

721 contains only $3(7)$ positive (negative) events. 


\section{TABLE and FIGURES}

\begin{tabular}{|l|l||l||l||l|}
\hline $\begin{array}{l}\text { Std dev. of low-freq. OLR (DJFM, } \\
\text { Southern) correlated with: }\end{array}$ & Correlations & $\begin{array}{l}\text { Partial corr. for } \\
\text { OLR.IOD/Niño3.4 }\end{array}$ & $\begin{array}{l}\text { Partial corr. for } \\
\text { DMI/Niño3.4 }\end{array}$ & $\begin{array}{l}\text { Partial corr. for } \\
\text { OLR.IOD/DMI }\end{array}$ \\
\hline OLR_IOD (SON) & $-0.52(99.8 \%)$ & $\begin{array}{l}-0.42 \text { (influence of } \\
\text { Niño3.4 removed) }\end{array}$ & - & $\begin{array}{l}-0.33 \text { (influence of } \\
\text { DMI removed) }\end{array}$ \\
\hline DMI (SON) & $-0.44(99 \%)$ & - & $\begin{array}{l}-0.30 \text { (influence of } \\
\text { Niño3.4 removed) }\end{array}$ & $\begin{array}{l}-0.11 \text { (influence of } \\
\text { OLR.IOD removed) }\end{array}$ \\
\hline Niño3.4 SST (SON) & $-0.34(95 \%)$ & $\begin{array}{l}-0.04 \text { (influence of } \\
\text { OLR.IOD removed) }\end{array}$ & $\begin{array}{l}-0.05 \text { (influence of } \\
\text { DMI removed) }\end{array}$ & - \\
\hline $\begin{array}{l}\text { std dev. of low-freq. SST (DJFM, } \\
\text { over the SCTR) from TMI/Reynolds }\end{array}$ & $\begin{array}{l}0.84(99 \%) / \\
0.62(99.8 \%)\end{array}$ & \multicolumn{1}{|l}{} \\
\hline
\end{tabular}

Table 1. First column: correlations of the standard deviation of LF OLR (DJFM, $55^{\circ} \mathrm{E}-165^{\circ} \mathrm{E}, 10^{\circ} \mathrm{S}-0^{\circ}$ ) with previous SON OLR_IOD, DMI, Niño3.4 SST over 1979-2008, and with the standard deviation of low-freq. SST in DJFM over the SCTR $\left(60^{\circ} \mathrm{E}-90^{\circ} \mathrm{E}, 8^{\circ} \mathrm{S}-3^{\circ} \mathrm{S}\right)$ from TMI (1998-2007)/Reynolds (1985-2007). Second to fourth column: partial correlations for different pairs, evidencing that rather than ENSO, it is OLR_IOD variability (and to a less extent the DMI) that explains most of the variance of the southern low-frequency MJO.

a) spectrum of SST in NDJFM, 1985-2007

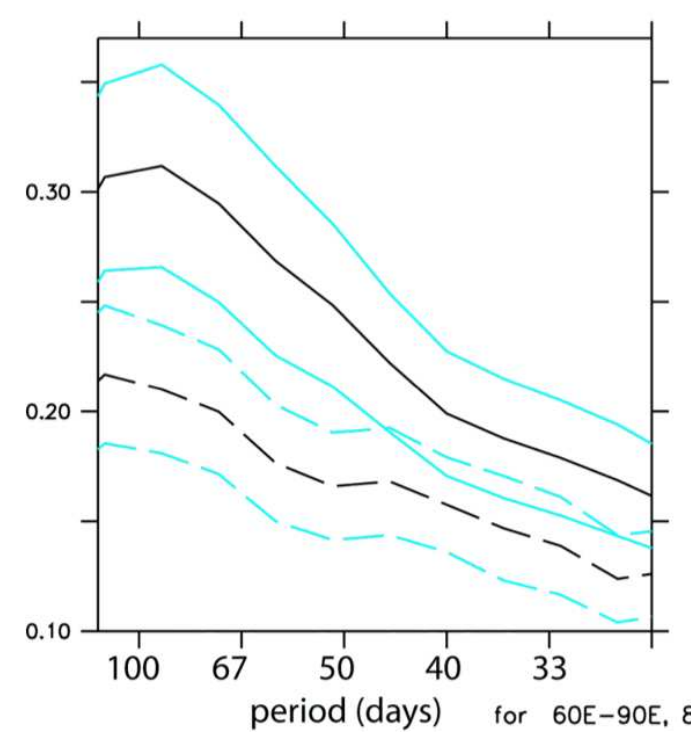

b) spectrum of OLR in NDJFM, 1979-2008

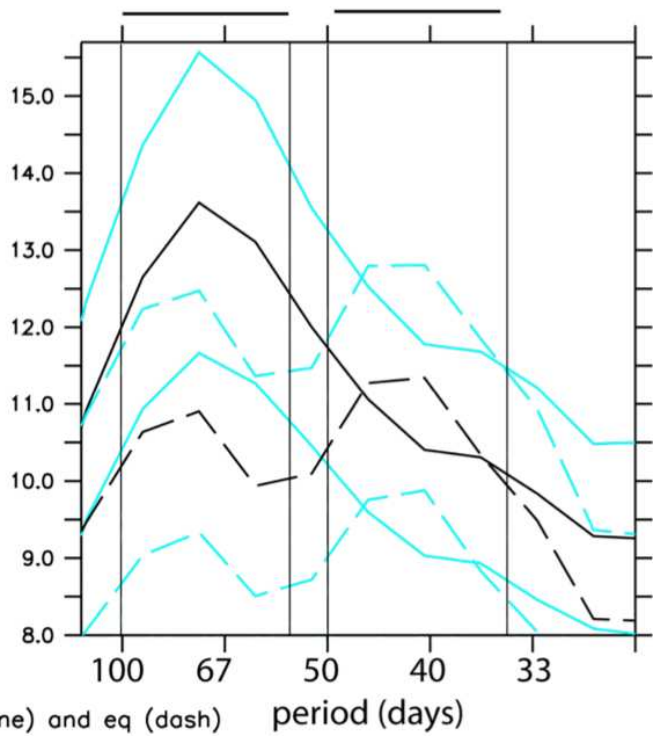

Fig. 1: Spectra (in amplitude) for $\mathrm{SST}\left({ }^{\circ} \mathrm{C}\right.$ day, left) and OLR $\left(\mathrm{W} \mathrm{m}^{-2}\right.$ day, right) along the thermocline ridge (at $8^{\circ} \mathrm{S}$; continuous black lines) and along the equator (dashed black lines) in NDJFM in the Indian Ocean (spectral amplitudes averaged over $\left.60^{\circ} \mathrm{E}-90^{\circ} \mathrm{E}\right)$. The vertical/horizontal lines on the right panel show the low and high frequency bands selected (55-100 days and 35-50 days). Light blue lines show the intervals confident at the $90 \%$ level. To reduce windowing effect, the component of the signal with periods greater than 125 days was removed before computing the spectra. 

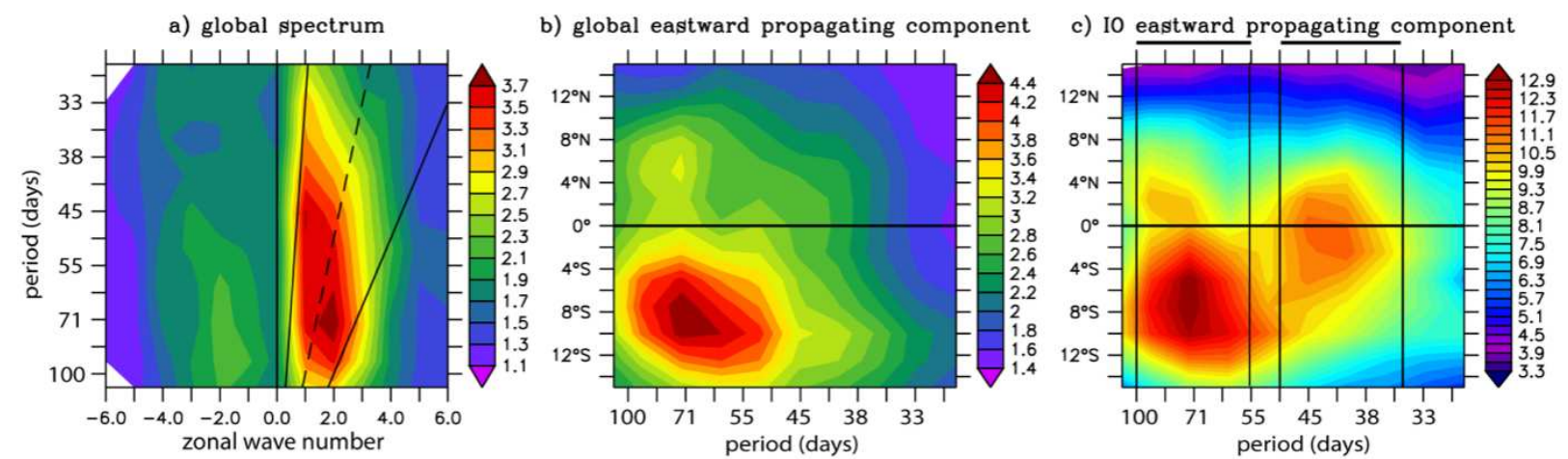

Fig. 2: (a) OLR spectrum (in amplitude, global, $10^{\circ} \mathrm{S}-5^{\circ} \mathrm{N}$ mean) ; (b,c) latitudinal distribution of OLR eastward propagating component (global in (b) and Indian Ocean only $\left(55^{\circ} \mathrm{E}-95^{\circ} \mathrm{E}\right)$ in (c) ) in austral summer (NDJFM). In (a), the $\mathrm{x}(\mathrm{y})$-axis is zonal wave number (period). The dashed line represents the conventional MJO speed $(5 \mathrm{~m} / \mathrm{s})$. In $(\mathrm{b}, \mathrm{c})$, the eastward propagating signal has been calculated by averaging spectrum over positive zonal wave numbers between the two continuous diagonal lines shown in (a) (i.e. between $2.5 \mathrm{~m} / \mathrm{s}$ and $15 \mathrm{~m} / \mathrm{s}$ speeds). In $(b, c)$, the $x(y)$-axis is the period (latitude). The vertical/horizontal lines on the right panel show the LF and HF bands. Unit is in $\mathrm{W} \mathrm{m}^{-2}$ day.

a) std dev $\mathrm{SST}(35-50 \mathrm{~d})$ DJFM

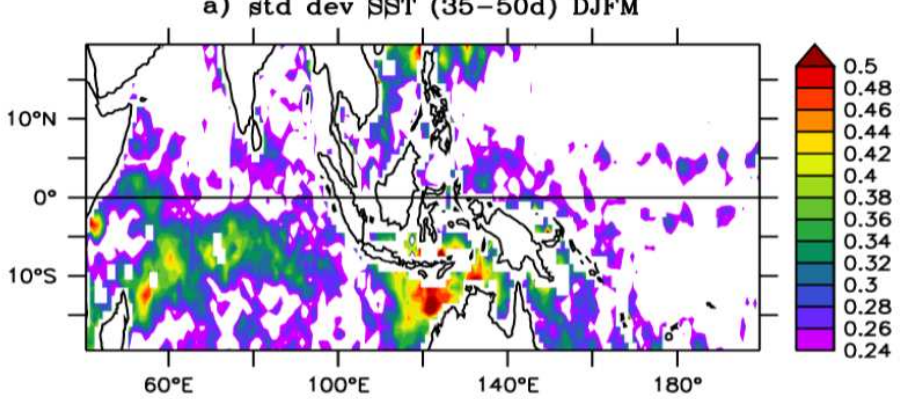

c) std dev SST (55-100d) DJFM

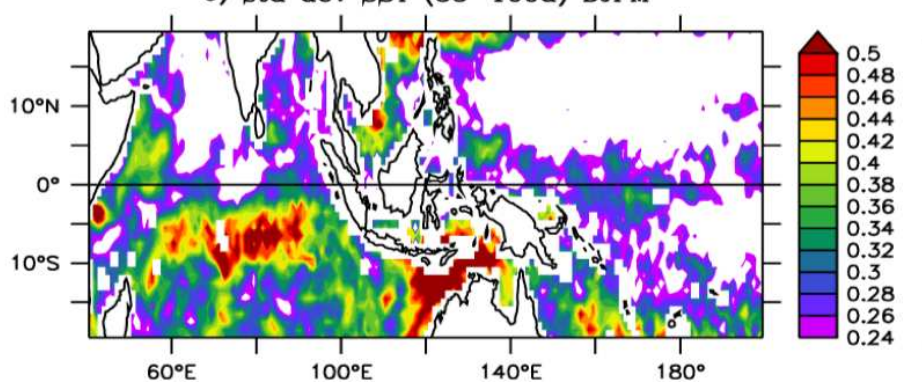

b) std dev OLR (35-50d) DJFM

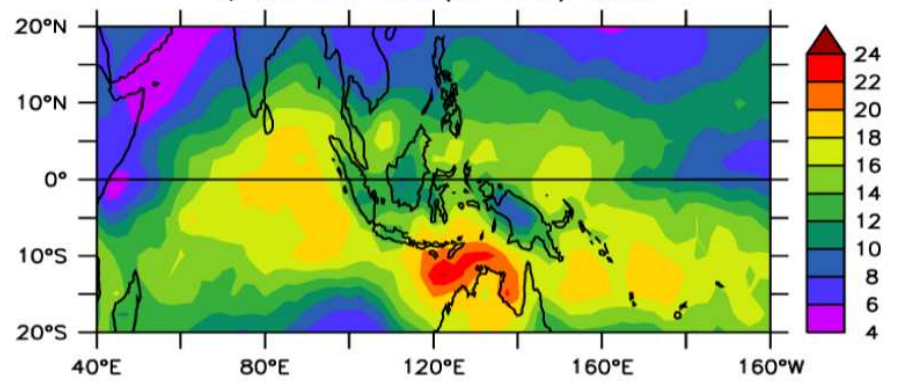

d) std dev OLR (55-100d) DJFM

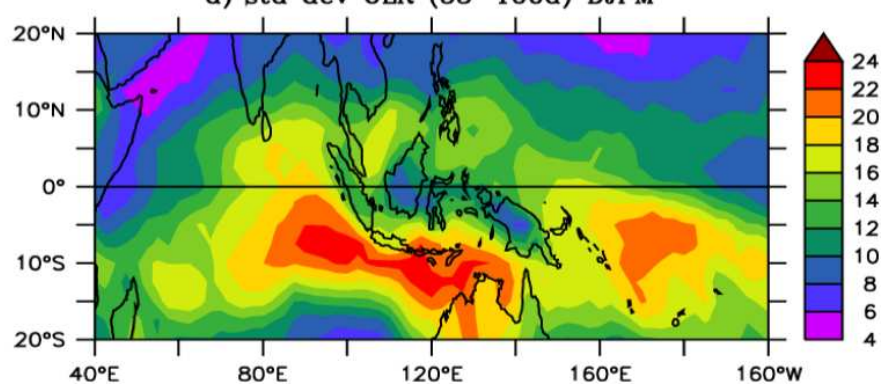

Fig. 3: maps of standard deviations of SST (TMI, left column; ${ }^{\circ} \mathrm{C}$ ) and OLR (right column; $\mathrm{W} \mathrm{m}^{-2}$ ) for MJO HF (upper row) and LF (lower row) bands in DJFM. 


\section{diurnal SST and SST prior to MJO onset in the Indian Ocean}

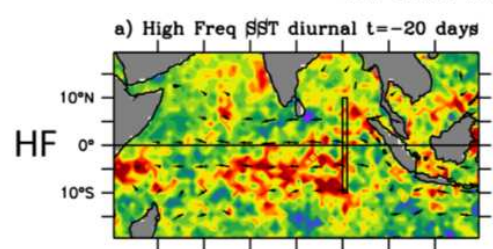

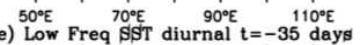

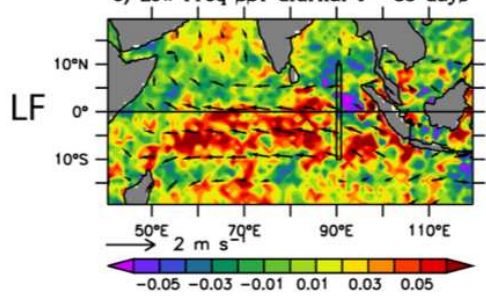

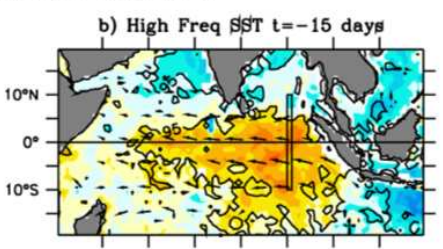

\begin{tabular}{l}
$50^{\circ} E$ \\
f) Low Freq $\$ 0^{\circ} \mathrm{EST} t=-30$ days \\
\hline $0^{\circ} \mathrm{E}$
\end{tabular}

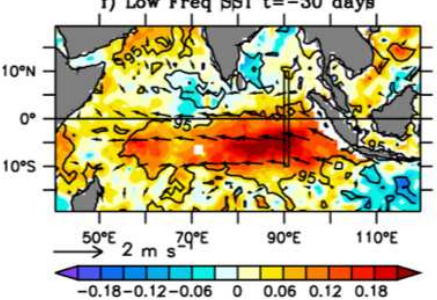

diurnal SST and SST prior to MJO passage in the maritime continent

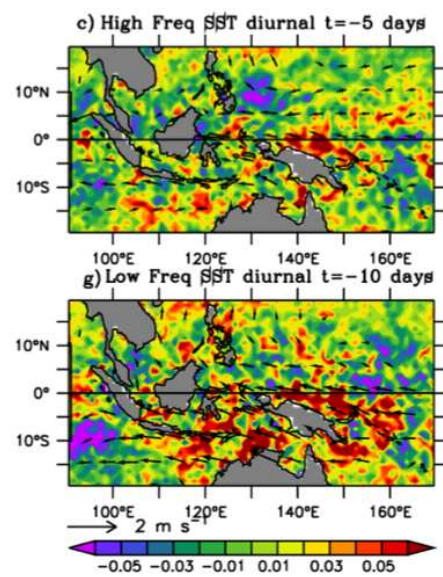

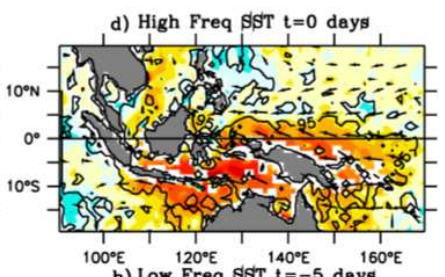

$100^{\circ} E$
h) Low Freq ${ }^{120^{\circ} E} \quad 14 T^{\circ} \mathrm{t}=-5$ days

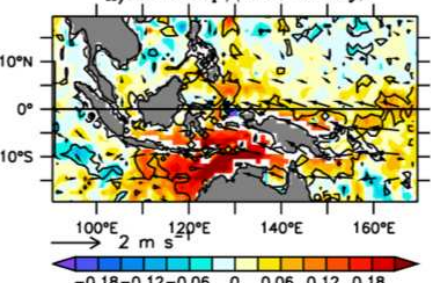

Fig. 4: difference between the HF (upper row) and LF (lower row) MJO composites, for SST diurnal amplitudes and daily SST, firstly prior to MJO onset in the Indian Ocean (left columns) and secondly prior to MJO propagation over the maritime continent (right columns). The weighted composites are at different lags for a negative intraseasonal OLR at $90^{\circ} \mathrm{E}, 10^{\circ} \mathrm{N}-10^{\circ} \mathrm{S}$ (location indicated by the black vertical bars) at $\mathrm{t}=0$ in DJFM. SST diurnal amplitude and daily SST are shown about a quarter to eighter period before the OLR composites of figure 5. Surface winds are plotted for significance higher than $85 \%$. Black contours show the $95 \%$ significant level.
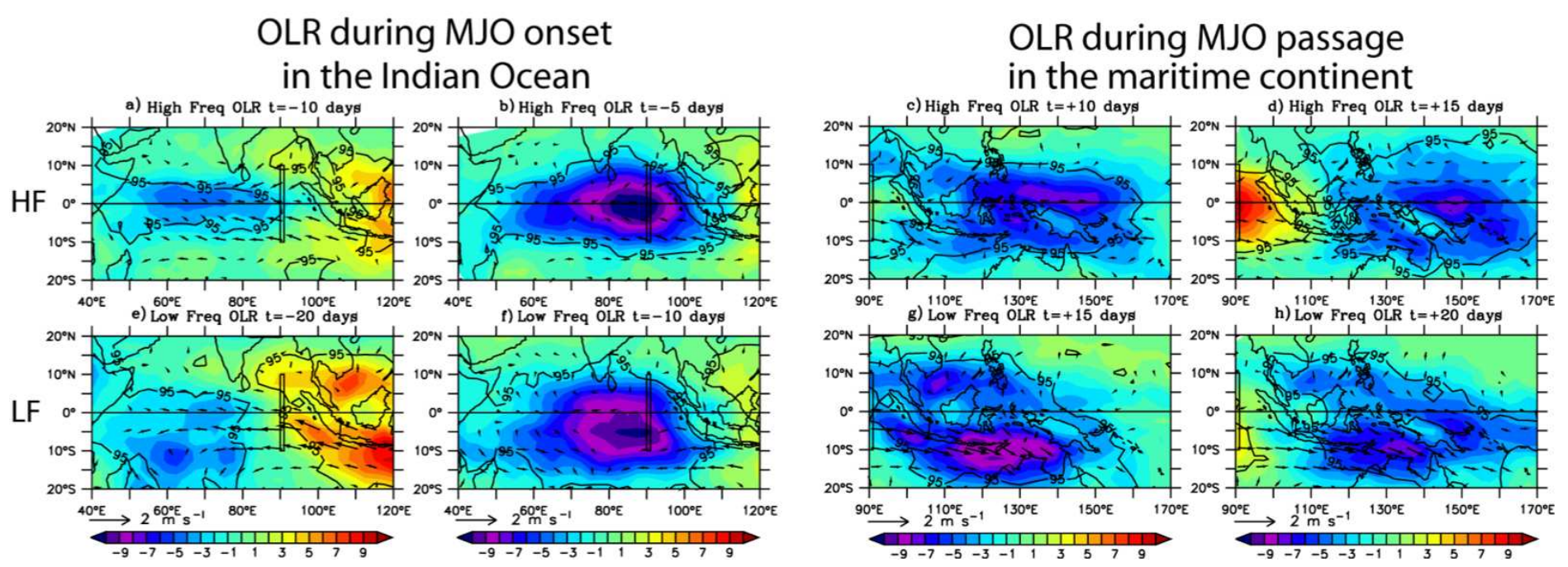

Fig. 5: similar to figure 4, but for OLR composites only, at various lags. 
a) SST and wind stress in SON

regressed on std dev of Low-Freq OLR in DJFM, $55^{\circ} \mathrm{E}-165^{\circ} \mathrm{E} ; 10^{\circ} \mathrm{S}-0^{\circ}$
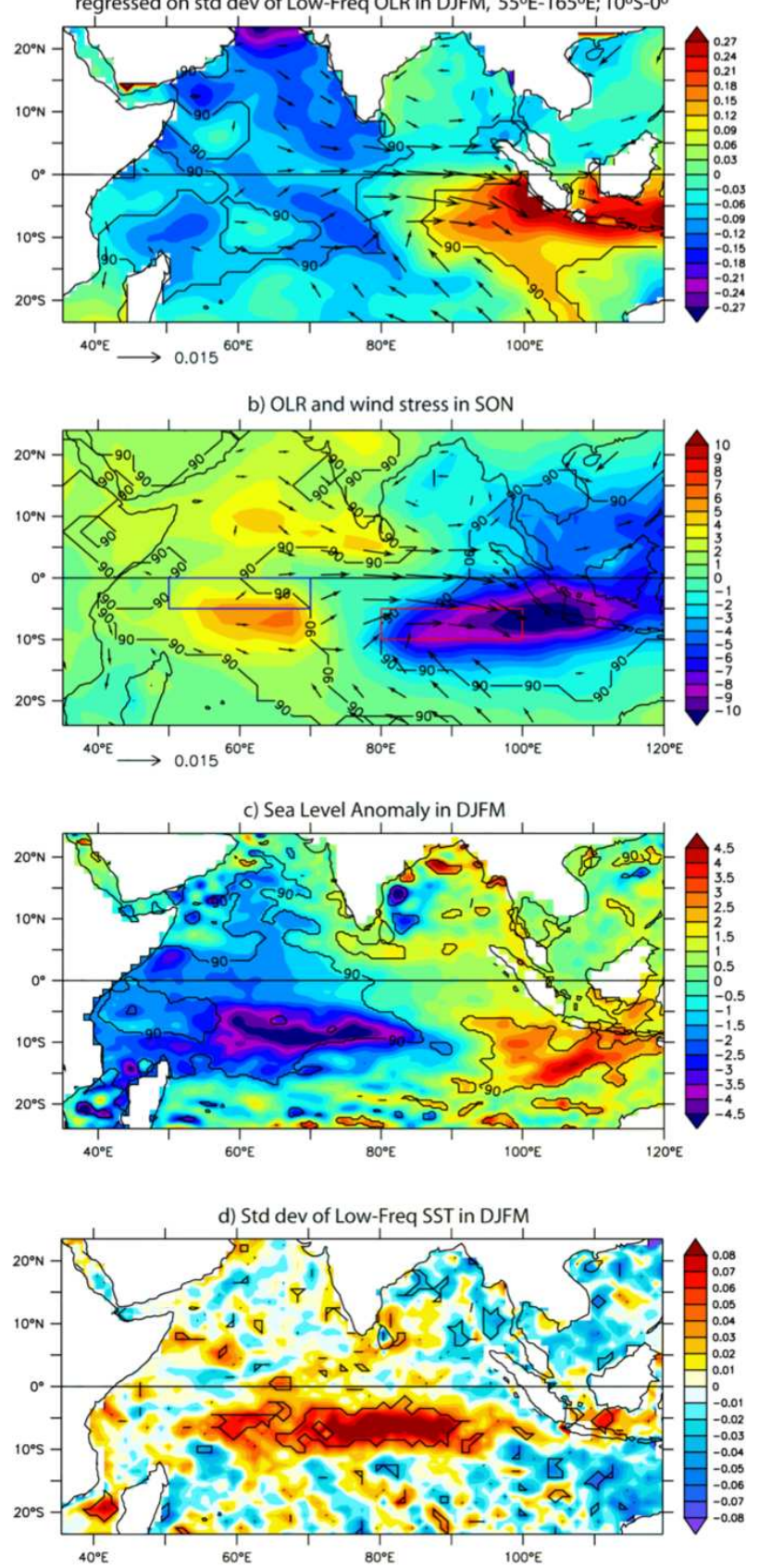

Fig. 6: ocean and atmosphere background state in boreal fall (SON) and winter (DJFM) regressed on southern LF-MJO activity in DJFM (OLR 55-100days, $\left.55^{\circ} \mathrm{E}-165^{\circ} \mathrm{E} ; 10^{\circ} \mathrm{S}-0^{\circ}\right)$. (a): mean SST $\left({ }^{\circ} \mathrm{C}, 1974-2007\right)$ and wind stress $\left(\mathrm{N} \mathrm{m}^{-2}, 1987-2007\right)$ in fall (SON) before strong low-frequency MJO. (b): same as (a) but for OLR (color, $\left.\mathrm{W} \mathrm{m}^{-2}, 1974-2007\right)$. (c): for mean SLA in DJFM (cm, AVISO, 1992-2007). (d): for standard deviation of lowfrequency SST in DJFM (TMI, 1998-2007). Surface winds are plotted for significance higher than $90 \%$. The $90 \%$ significant level is added in black contours. The boxes defining the OLR-IOD index are shown in (b). 
a) spectrum of SST in NDJFM, 1985-2007

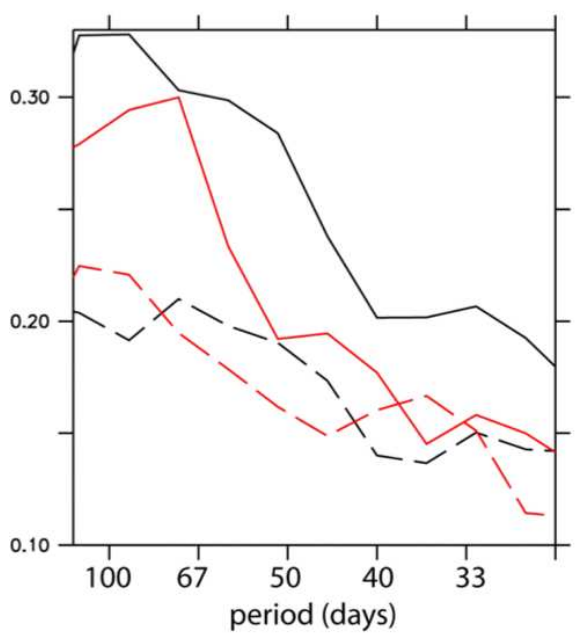

b) spectrum of OLR in NDJFM, 1979-2008

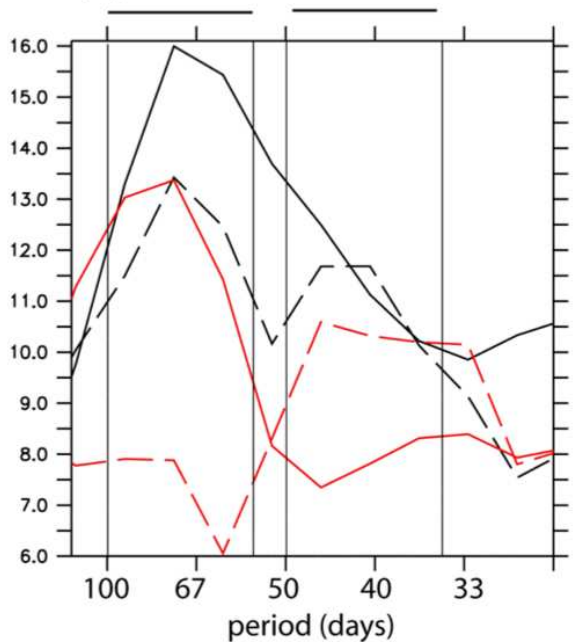

for 60E-90E, 8S (line) and eq (dosh), ofter negative (block) and positive (red) 100 in SON

Fig. 7: same as Fig. 1, but for boreal winters following negative (black) and positive (red) IOD in fall.
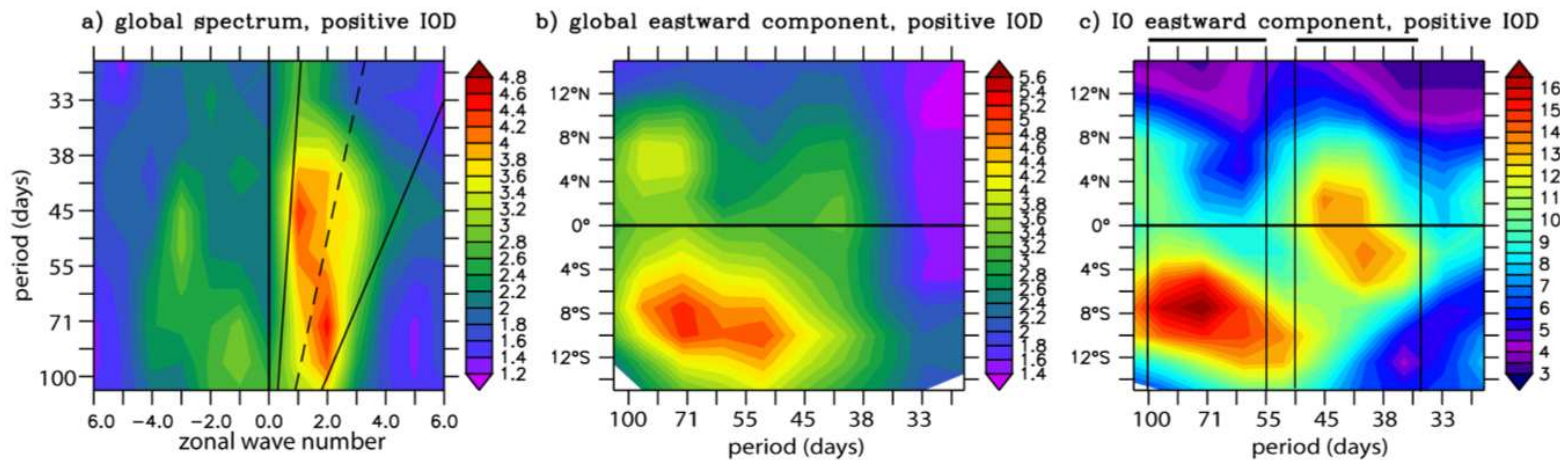

d) global spectrum, negative IOD

e) global eastward component, negative IOD

f) IO eastward component, negative IOD
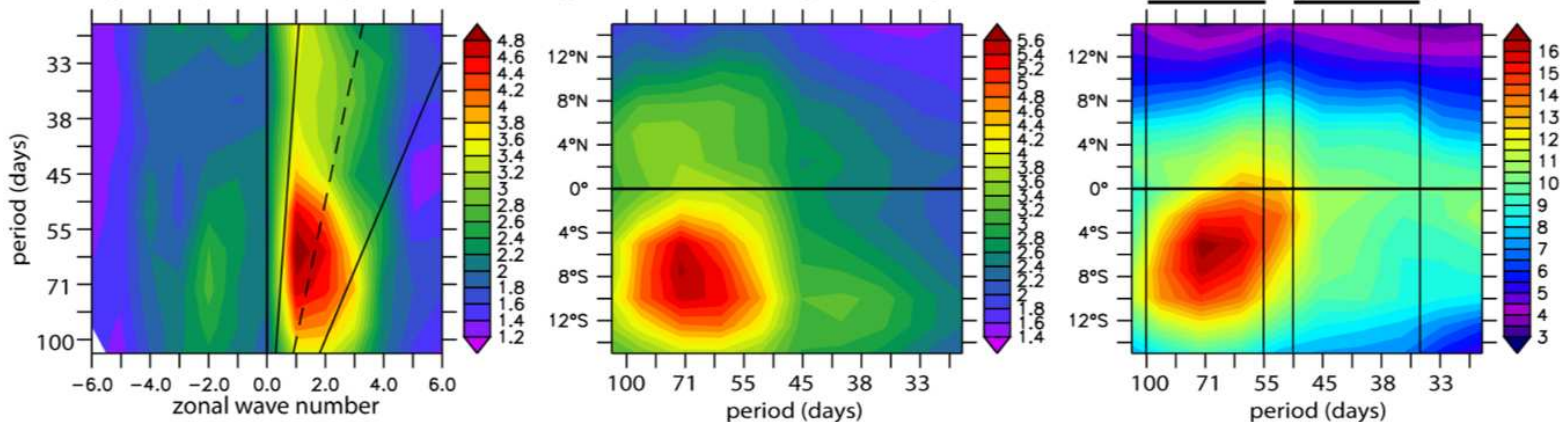

Fig. 8: longitude-time spectrum (left column), and latitudinal distribution of eastward propagating component globally (middle column) and in the Indian Ocean (right column), for OLR in DJFM, after positive IOD (upper row) and negative IOD (lower row) in SON (similar method to Fig. 2). 
a) positive IOD $\$ S T$ diurnal $(t=-20 d$ minus $t=0 d)$ b) positive IOD $\$ S T$ T $=-15$ days

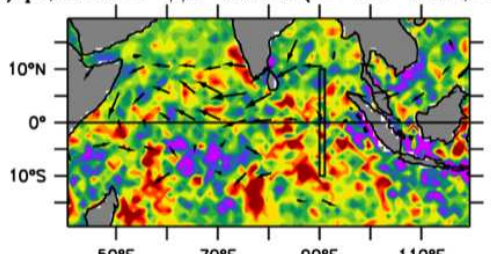

$50^{\circ} \mathrm{E} \quad 70^{\circ} \mathrm{E} \quad 90^{\circ} \mathrm{E} \quad 110^{\circ} \mathrm{E}$
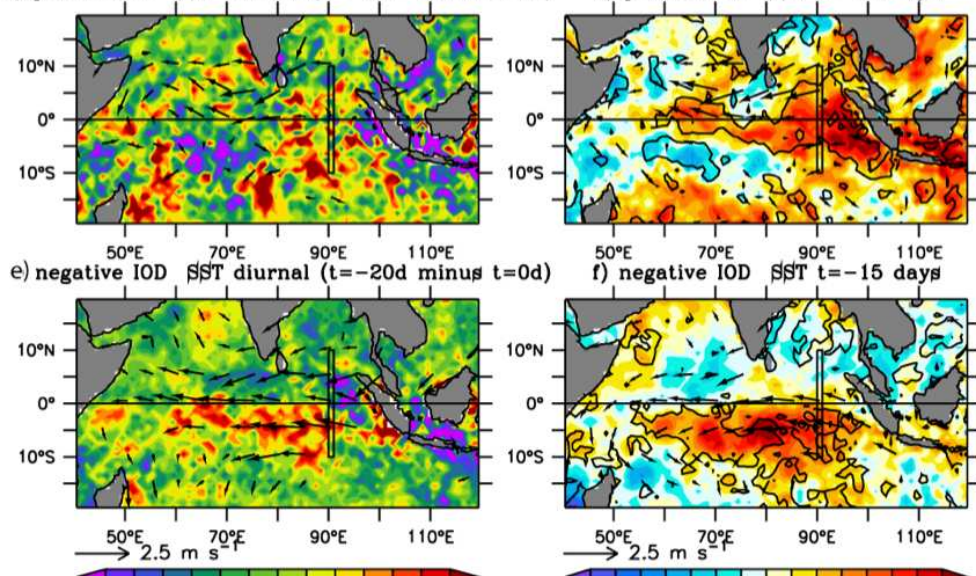

$50^{\circ} \mathrm{E}$
f) negative IOD
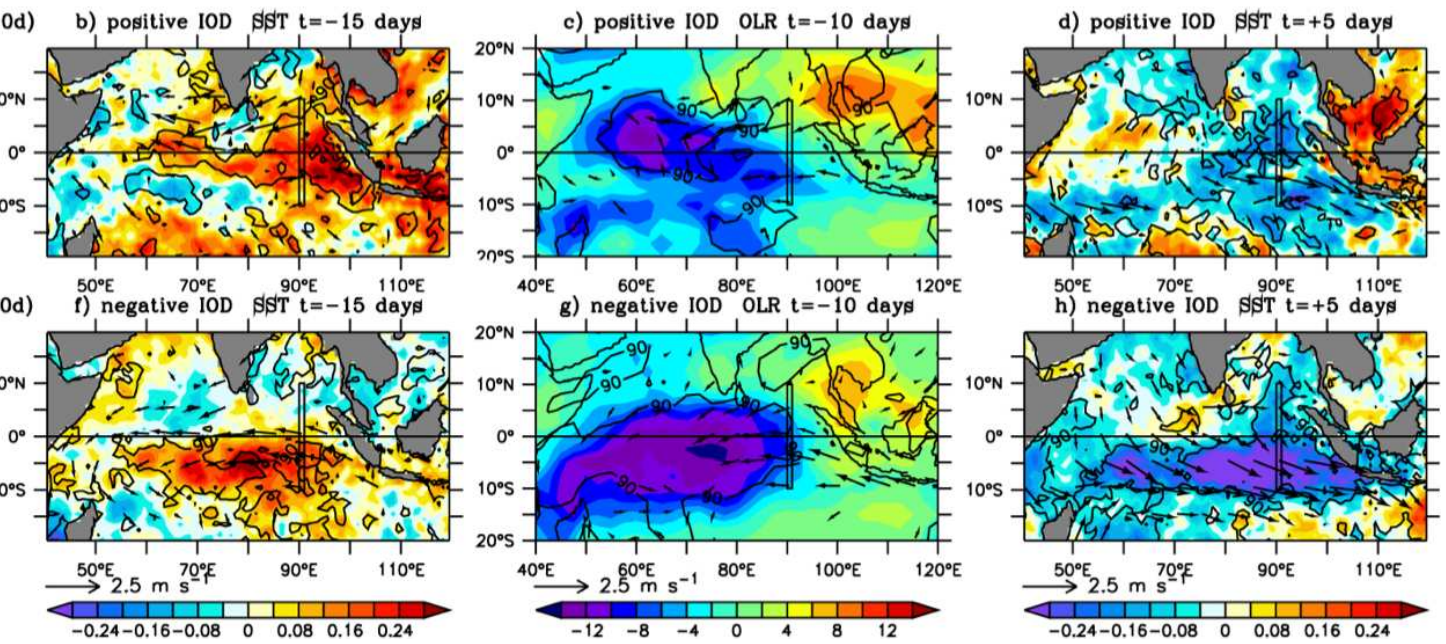

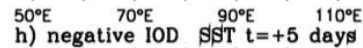

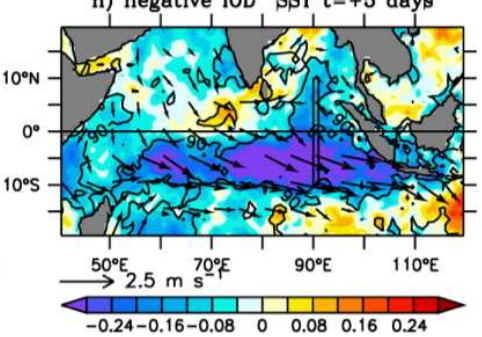

Fig. 9: MJO weighted composites in winter after positive (upper row) and negative (lower row) IOD conditions in fall: for SST $\left(2^{\text {nd }}\right.$ column $)$ and OLR $\left(3^{\text {rd }}\right.$ column $)$ intraseasonal anomalies during MJO onset, and for intraseasonal SST just after the passage of MJO active phase $\left(4^{\text {th }}\right.$ column $)$, in DJFM. Surface winds are plotted for significance higher than $85 \%$. The $90 \%$ significant level is added in black contours. In the first column, the difference of the $t=-20$ days and $t=0$ composites for the diurnal amplitude of SST (its total anomaly, no intraseasonal filtering) is plotted to remove the strong interannual signal (cf. fig. 11e,j), as the latter can not be trivially removed otherwise due to missing data constraints. The MJO index used here has been filtered in the broad 30120days band, so as to let MJO timescale unconstrained a priori (see text for details).
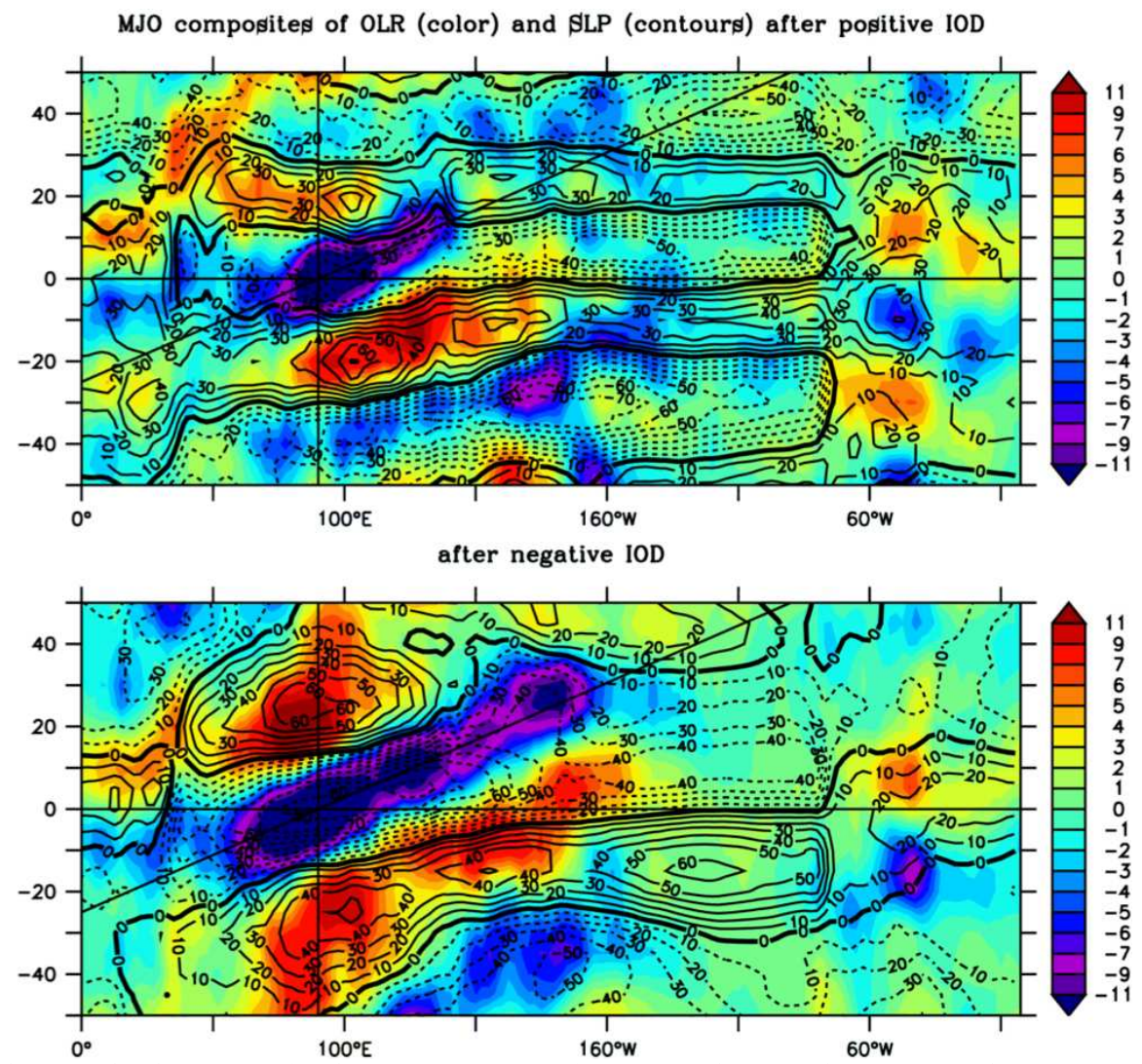

Fig. 10: time-longitude diagrams for lag-composites of OLR (color, to show MJO slow propagation in IndoPacific ITCZ-SPCZ) and SLP (contour, to evidence the circum-equatorial propagation as faster moist Kelvin waves), following different IOD conditions in fall: positive (upper) and negative (lower). The diagonal line shows the conventional MJO speed $(5 \mathrm{~m} / \mathrm{s})$. Latitudinal averaging is done over $15^{\circ} \mathrm{S}-5^{\circ} \mathrm{N}$ to capture the average propagation of MJO convection, shifted to the south during boreal winter. The fields composited here have not been high-pass filtered to limit time-aliasing. The MJO index used here is filtered over the broad 30-120days band, as in Fig. 9. 

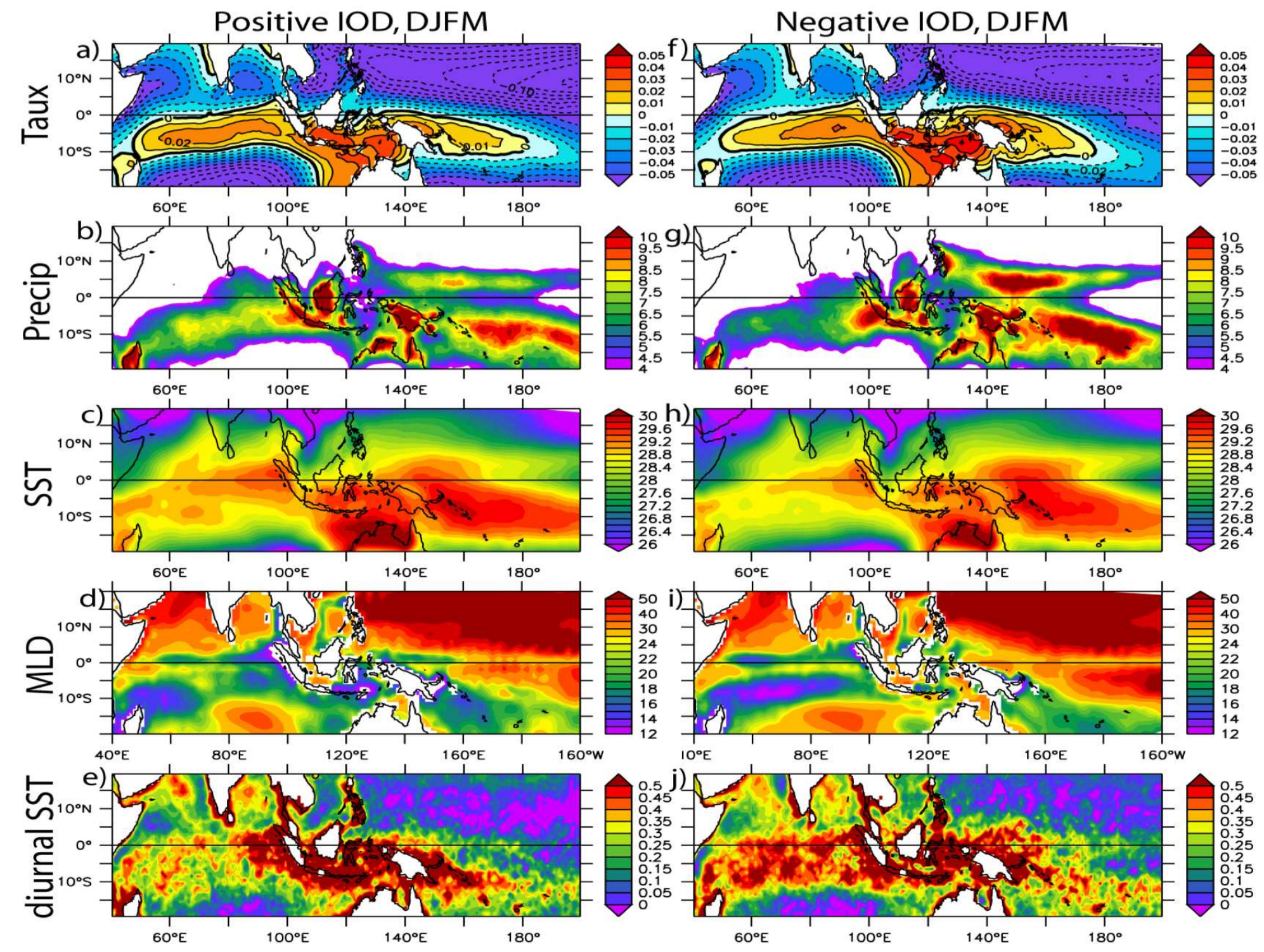

Fig. 11: Composites of mean DJFM state after positive (left column) and negative (right column) IOD. $1^{\text {st }}$ line: zonal wind stress (SSMI/ERS1-2/Quikscat; N/ $\left.\mathrm{m}^{2}\right), 2^{\text {nd }}$ line: precipitation $(\mathrm{mm} / \mathrm{d}, \mathrm{GPCP}), 3^{\text {rd }}$ line: $\mathrm{SST}\left({ }^{\circ} \mathrm{C}\right.$, ERSST/Reynolds), $4^{\text {th }}$ line: ocean mixed layer (m, from CERFACS-ENSEMBLES ocean reanalysis), $5^{\text {th }}$ line: amplitude of SST diurnal cycle ( ${ }^{\circ} \mathrm{C}$, AVHRR). 7 (14) positive (negative) IOD events were used for the longest time series (1974-2007, SST, OLR and MLD). However, the shortest record (SST diurnal cycle) contains only 3 (7) positive (negative) events. 